\title{
Extent of Intracortical Arborization of Thalamocortical Axons as a Determinant of Representational Plasticity in Monkey Somatic Sensory Cortex
}

\author{
E. Rausella and E. G. Jones \\ Department of Anatomy and Neurobiology, University of California-Irvine, Irvine, California 92717
}

The extent of intracortical arborization of individual thalamocortical axons in area $3 \mathrm{~b}$ of the somatic sensory cortex and the degree of overlap in the cortical projections of relay cells in the ventral posterior nucleus of the thalamus were examined in macaque monkeys. Paired intracortical deposits of Fast blue (FB) and Diamidino yellow (DY) separated by 100-1500 $\mu \mathrm{m}$ were made by inserting crystals of dye into the tracks of tungsten microelectrodes used to record receptive field data on area $3 b$ cells.

Each injection gave retrograde labeling of one or more clusters of cells extending in elongated anteroposterior arrays through the ventral posterior medial (VPM) or ventral posterior lateral (VPL) nucleus. Double-labeled cells were only found when the distance between the centers of the dye deposits was less than $600 \mu \mathrm{m}$. With interdeposit distances greater than $600 \mu \mathrm{m}$, most clusters of retrogradely labeled cells had a majority of cells labeled by FB or DY. However, even with interdeposit distances of 1-1.5 mm the labeled clusters also contained significant numbers of cells labeled with the other dye.

These results and an accompanying regression analysis indicate that the extent of intracortical arborization of single thalamocortical axons in area $3 \mathrm{~b}$ is no greater than 600 $\mu \mathrm{m}$. However, adjoining cells in the same part of the thalamic body representation can project to cortical targets as discrepant as $1.5 \mathrm{~mm}$. It is proposed that the fine grain of the cortical representation depends upon inputs from the majority population of each thalamic cell cluster. However, divergent and convergent projections from minority populations of the clusters form a preexisting basis for rapid changes in the cortical representational map under activity-dependent conditions.

[Key words: retrograde tracing, ventral posterior thalamus, somatosensory maps, area $3 b$, macaques, convergence, divergence]

\footnotetext{
Received Sept. 21, 1994; received Jan. 10, 1995; accepted Feb. 8, 1995.

This work was supported by Grants NS21377 and NS22317 from the National Institutes of Health, U.S. Public Health Service. We are indebted to Dr. Ariel Agmon for much help with the quantitative analysis of these data and to Dr. Marco Molinari and Dr. Angel Vinuela for assistance with some of the experiments.

Correspondence should be addressed to Dr. Edward G. Jones at the above address.

aPresent address: Department of Morphology, Autonomous University, Madrid, Spain

Copyright (C) 1995 Society for Neuroscience $0270-6474 / 95 / 154270-19 \$ 05.00 / 0$
}

In primary somatosensory cortex of primates the contralateral half body is represented in exquisitely detailed maps (Paul and Mountcastle, 1959b; Paul et al., 1972; Dreyer et al., 1975; Kaas et al., 1979; Merzenich et al., 1978; Nelson et al., 1980; Mountcastle, 1984), the details of which reflect peripheral innervation density (Mountcastle and Powell, 1959) and submodality of affcrent input (Powell and Mountcastle, 1959; Phillips et al., 1970; Sur et al., 1980, 1981, 1984; Iwamura et al., 1983, 1988, 1993).

The representation is not static. It shows variation hetween individuals (Kaas et al., 1987; Merzenich et al., 1987; Wall et al., 1993) and under activity-dependent conditions. Perturbations at the periphery (Kaas et al., 1983; Merzenich et al., 1983a,b; Wall et al., 1986, 1992a,b; Cusick et al., 1990; Kaas, 1991) and behavioral enhancements (Clark et al., 1988; Jenkins et al., 1990a,b; Allard et al., 1991; Recanzone et al., 1992) cause representations of a small body part to expand or contract in relation to representations of adjacent parts. With massive loss of sensory input maintained over a protracted period, representations of a larger division of the body may expand into territory normally occupied by another (Pons et al., 1992).

Activity-dependent shifts in representations in somatosensory cortex may depend upon sprouting of thalamocortical or intracortical connections into new territories (Puns el al., 1992) and/ or upon functional expression of preexisting but hitherto functionally suppressed thalamic and/or intracortical connections (Kaas et al., 1983; Jacobs and Donoghue 1991; Lund et al., 1994). This may result from activity-dependent up- and downregulation of gene expression for transmitter- and receptor-related molecules that alters the balance of excitation and inhibition in the cortex (Jones, 1990, 1993). Before potential mechanisms can be explored further, it is essential to have an understanding of the normal extent of the terminal arborizations of the relevant fiber systems.

For the thalamocortical system, the most important data lacking are those that pertain to the extent of intracortical distribution of individual thalamocortical fibers and of groups of fibers arising from thalamic cells with the same receptive fields and submodality properties. In macaque monkeys, a small number of putatively thalamic afferent fibers had single, focal domains of termination approximately $500 \mu \mathrm{m}$ in extent in area $3 \mathrm{~b}$ (Garraghty and Sur, 1990), but the extent of branching deep in the white matter was not determined. A smaller number of these axons displayed more extensive branching and formed multiple foci of terminations scattered over $2 \mathrm{~mm}$ of cortex.

Anterograde and retrograde tracing studies of projections from the ventral posterior nucleus of macaques have involved relatively large injections of tracer so that the results do not provide 
Table 1.

\begin{tabular}{|c|c|c|c|c|c|c|}
\hline $\begin{array}{l}\text { Case } \\
\text { number }\end{array}$ & $\begin{array}{l}\text { Receptive field at the } \\
\text { injection site }\end{array}$ & $\begin{array}{l}\text { Injection } \\
\text { site }\end{array}$ & $\begin{array}{l}\text { Inter- } \\
\text { injection } \\
\text { distance } \\
(\mu \mathrm{m})\end{array}$ & $\begin{array}{l}\text { Thalamic } \\
\text { nucleus }\end{array}$ & $\begin{array}{l}\text { Double } \\
\text { labeling }\end{array}$ & $\begin{array}{l}\text { Antero } \\
\text { posterior } \\
\text { extent of } \\
\text { thalamic } \\
\text { labeling } \\
(\mu \mathrm{m})\end{array}$ \\
\hline & DY, upper peroneal region & & & & & \\
\hline $51 \mathrm{~L}$ & $\begin{array}{l}\text { FB, upper peroneal region } \\
\text { DY, zygomatic region }\end{array}$ & Area $3 b$ & 100 & VPL & +++ & 675 \\
\hline $53 \mathrm{~L}$ & $\begin{array}{l}\text { FB, zygomatic region } \\
\text { DY, uppcr lip }\end{array}$ & Area $3 b$ & 250 & VPM & ++ & 850 \\
\hline $51 \mathrm{R}$ & $\begin{array}{l}\text { FB, upper lip } \\
\text { DY, medial aspect of the knee }\end{array}$ & Area 3b & 280 & VPM & ++ & 1200 \\
\hline $53 \mathrm{R}$ & $\begin{array}{l}\text { FB, medial aspect of the knee } \\
\text { DY, great toe }\end{array}$ & Area $3 b$ & 300 & VPL & ++ & 850 \\
\hline $58 \mathrm{R}$ & $\begin{array}{l}\text { FB, lateral plantar digital pad } \\
\text { DY, lateral inguinal region }\end{array}$ & Area $3 b$ & 600 & VPL & + & 600 \\
\hline $52 \mathrm{~L}$ & $\begin{array}{l}\text { FB, medial inguinal region } \\
\text { DY, face }\end{array}$ & Area $3 b$ & 1100 & VPL & $\mathrm{O}$ & 850 \\
\hline $43 \mathrm{R}$ & $\begin{array}{l}\mathrm{FB}, \text { face } \\
\mathrm{DY} \text {, face }\end{array}$ & Area $3 b$ & 1160 & VPM & $\mathrm{O}$ & 900 \\
\hline $45 R$ & $\begin{array}{l}\text { FB, face } \\
\text { DY, upper lip }\end{array}$ & Area $3 b$ & 1310 & VPM & $\mathrm{O}$ & 1120 \\
\hline $52 \mathrm{R}$ & FB, upper lip & Area 3b & 1500 & VPM & $\mathrm{O}$ & 850 \\
\hline
\end{tabular}

the detail necessary for an evaluation of the extent of cortical projection of small groupings of thalamic cells. Recent retrograde studies (Darian-Smith et al., 1990; Darian-Smith and Darian-Smith, 1993), suggest that earlier studies (Jones et al., 1979; Nelson and Kaas, 1981) may have underestimated the extent of intracortical arborization of thalamocortical fibers. In a previous anterograde study, injection of tiny amounts of tritiated amino acids at physiologically defined sites in the ventral posterior nucleus resulted in labeling of axonal terminations in multiple foci scparated by gaps in area 3b (Jones et al., 1982). All these findings imply that a group of thalamic cells representing the same localized constellation of peripheral receptors could potentially gain access to a wider zone of cortex than revealed in conventional multiunit mapping studies and form a basis for expansion of a representation under appropriate conditions.

The present study shows the extent of thalamic cells providing afferents to physiologically defined, small parts of the somatic sensory cortical representation and the extent of overlap in the projections of individual thalamic cells to these parts.

A preliminary report has appeared (Rausell et al., 1993).

\section{Materials and Methods}

Electrophysiological localization and fuorochrome injection. Six normal adult monkeys (two Macaca fuscata and four Macaca mulatta) were used (Table 1). The animals were anesthetized with intramuscular ketamine, and maintained on intravenous Nembutal at approximately $12 \mathrm{mg} / \mathrm{kg} / \mathrm{hr}$. They were placed in a stereutaxic frame, and small craniotomies where performed in order to expose the medial and/or lateral aspects of the postcentral gyrus. In several cases (Table 1), both left and right hemispheres were used. Tungsten microelectrodes (resistance approximately $5 \mathrm{M} \Omega$ ) were inserted into the cortex at the medial or lateral end of the central sulcus where area $3 \mathrm{~b}$ comes to the surface (Powell and Mountcastle, 1959a; Roberts and Akert, 1963), and advanced in steps of $100 \mu \mathrm{m}$. Multiunit discharges were evoked in response to light tactile stimuli, and the receptive fields were mapped. Two loci, $1.5 \mathrm{~mm}$ or less apart, in which responses were evoked from overlapping or nonoverlapping receptive fields were identified. In five cases (Table 1), recording sites containing neurons with overlapping receptive fields were selected; in four cases, sites containing neurons with nonoverlapping receptive fields were selected. Micropipettes containing $8 \%$ Fast blue (FB) or 5\% Diamidino yellow (DY) were dipped into the dry dyes so that small crystals of the dye adhered to the tip. The micropipettes were then used to push one or more crystals of the dye into the two identified tracks left by the tungsten microelectrodes. FB was inserted at one site and DY at the second.

The animals were allowed to survive for 2 weeks. Then they were given an overdose of Nembutal and perfused through the ascending aorta with normal saline followed by a solution of $4 \%$ paraformaldehyde and $0.2 \%$ glutaraldehyde in $0.1 \mathrm{M}$ phosphate buffer. The brain was removed and blocked; the blocks were infiltrated with $30 \%$ sucrose in $0.1 \mathrm{M}$ phosphate buffer at $4^{\circ} \mathrm{C}$ and subsequently frozen in dry ice.

Tissue processing and analysis. Frozen blocks of cerebral cortex containing the FB and DY deposits were sectioned parasagittally on a sliding microtome at $50 \mu \mathrm{m}$; blocks containing the thalamus were cut frontally at $25 \mu \mathrm{m}$ or alternating at $20 \mu \mathrm{m}$ and $40 \mu \mathrm{m}$. Sections were mounted immediately from phosphate buffer on clean slides, and after partial drying were coverslipped in a 3:1 mixture of glyccrol and 0.1 M phosphate buffer.

Sections were examined with an epifluorescence microscope equipped with a broad band ultraviolet excitation filter. The stage of the microscope was equipped with optical encoders interfaced to a personal computer using the Minnesota Datametrics MD2 plotting system. Computer generated maps were used to mark the outlines of the sections, landmarks such as blood vessels, and the locations of dye deposits in the cerebral cortex and of retrogradely labeled cells in the thalamus. The sections of the cortex were then remounted on gelatin-coated slides, dried, and stained with thionin. These Nissl-stained sections were then traced with a camera lucida, cytoarchitectonic borders werc marked and the tracings were overlapped onto the previously generated maps of dye deposits. In this way, the areal location and the laminar and horizontal extent of the FB and DY deposits were identified. Only injections in area $3 b$ were included for study. Any that involved area 1 were excluded from the series. Pushing the crystals of FB and DY into the cortex, minimized diffusion of the dyes. However, a central core of dense dye deposit was invariably surrounded by a narrow zone of weaker density, 80 to $100 \mu \mathrm{m}$ in extent. This was wider for FR deposits than for DY deposits. In calculating the extent of cortex affected by each dye, the outer limit of the weaker zone was taken as the outer limit of the in- 


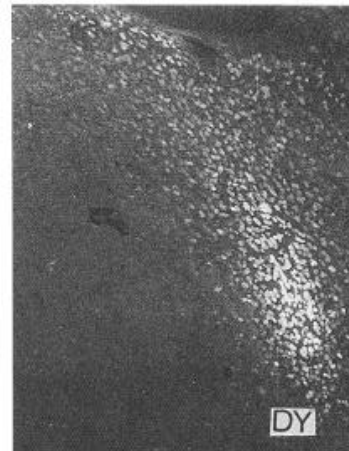

A
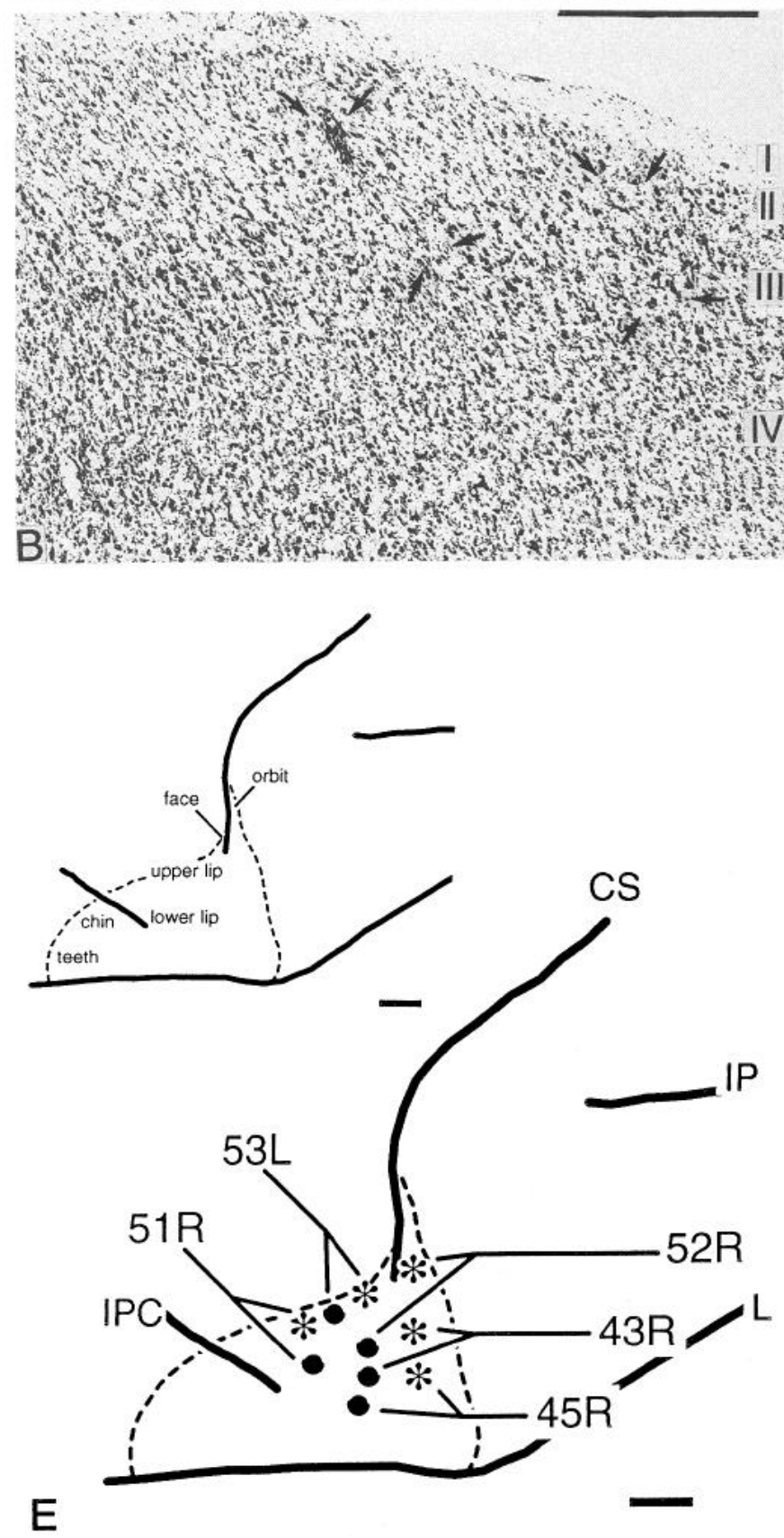
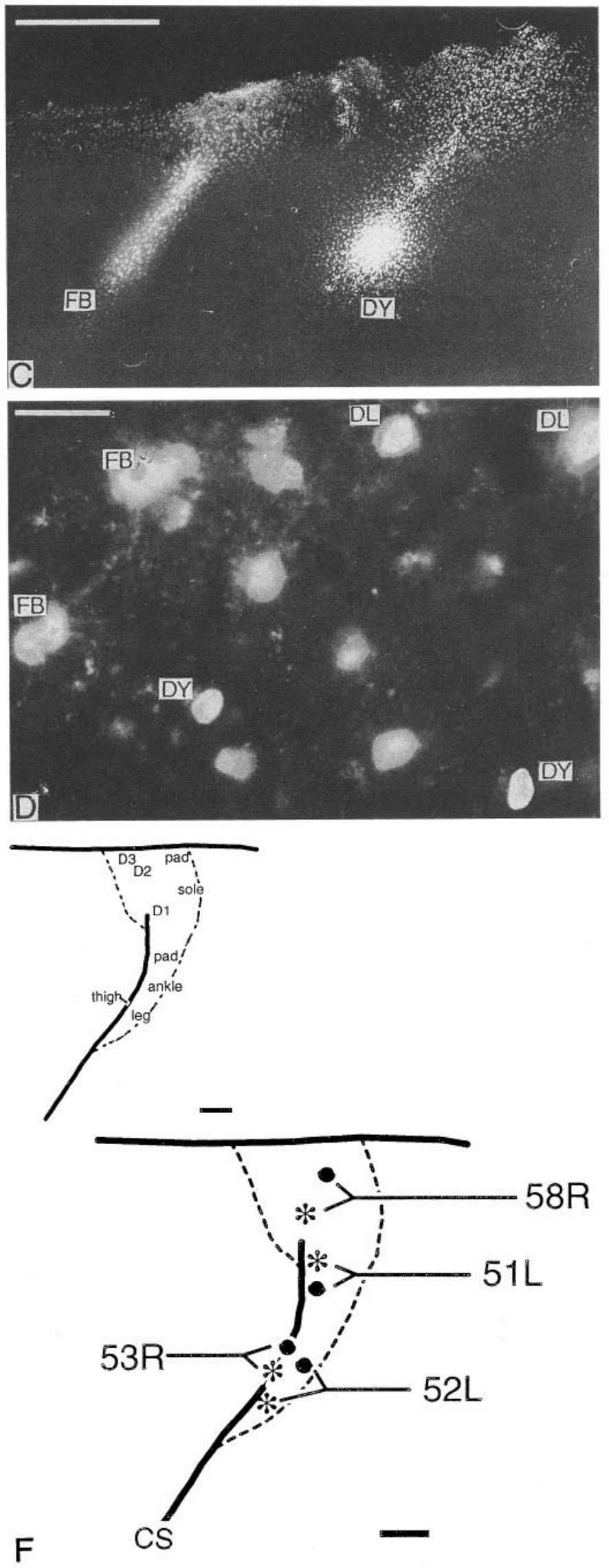
jection. The distance between the $\Gamma \mathrm{B}$ and DY deposits in each pair was determined by measuring the distance between the cores of the deposits in layers III and IV (Fig. 1).

In the thalamus, the distributions of all neurons retrogradely labeled with FB or DY were plotted at high magnification $(1000 \times)$ with the MD2 system. In half the cases, which were chosen randomly, the thalamus had been cut in alternating series of 20 and $40 \mu \mathrm{m}$ sections in order to ensure that a lack of double-labeled neurons was not a consequence of nonoptimal section thickness. No differences were noted. After all sections had been plotted under epifluorescence, they were reassembled in two alternating series; one was remounted and stained with thionin, and the other was stained histochemically for cytochrome oxidase (CO, Wong Riley, 1979) and subsequently mounted. The restained sections were scanned into a MacIntosh Quadra 950 computer, using a Nikon LS-3510 film scanner, the images saved as PICT files and exported to Adobe PHOTOSHOP. Similar scans of the previously generated maps of labeled cell distribution were then made using a Hewlett Packard ScanJet IICX flatbed scanner. The two scans were superimposed in the computer to generate new maps in which all the Nissl-stained neurons located in the same area (Figs. 2, 3) or the densities of $\mathrm{CO}$ staining were plotted in relation to the retrogradely labeled cells (Figs. 4-6).

All the original maps showing the distribution of retrogradely labeled cells in the series of thalamic sections were copied on transparent acetate sheets and put in register by using the sectioned profiles of blood vessels as landmarks. FB-, DY-, and double-labeled neurons were color coded and the coordinates of each labeled neuron were transferred to a data sheet (QUATROPRO) by means of a digitizing tablet and SIGMASCAN software (Jandel). This provided a mathematical matrix used to operate a stereological program, from which three-dimensional reconstructions of the whole labeled population could be obtained (Acrospin, DELTA(GRAPH). The reconstructions were rotated to provide frontal, parasagittal, and dorsal views of the cloud of retrogradely labeled neurons in the ventral posterior (VP) nucleus of the thalamus (Figs. 7-10). The total number of retrogradely labeled neurons, the relative proportions of FB-, DY-, and double-labeled neurons were calculated, and correlations were made between the relative proportions and the distance between the centers of the dye deposits. In this way, the maximum distance between two cortical deposits at which the probability of finding double-labeled neurons in VP was minimal, was calculated. This parameter was then used to predict the extent of arborization of thalamocortical axons in SI and the degree of overlap in the arborizations of axons arising from neurons that were neighbors in VP.

\section{Results}

\section{General features}

All the injection sites were located in area $3 b$ of the primary somatosensory cortex, as determined cytoarchitectonically, and were centered in layers III-IV with no extension into the white matter and relatively little spread over the cortical surface (Fig. 1). Table 1 shows the location of the receptive fields at the injected sites in each case. The separation between the FB and DY deposits in each pair varied from $100 \mu \mathrm{m}$ to $1500 \mu \mathrm{m}$. Nine cases in which there was no overlap of the dyes in the cortex were considered for study.

Table 2 shows the absolute and relative numbers of FB-, DY-, and double-labeled cells in the VP nucleus of each case. Retrogradely labeled neurons were located in the ventral posterior medial nucleus (VPM) in five cases and in the ventral posterior lateral nucleus (VPL) in four cases, depending on the location of the deposits in relation to the somatotopic map in area $3 \mathrm{~b}$ (Fig. 1E,F). The number of neurons retrogradely labeled with each dye varied, depending on the extent of cortex affected by the corresponding deposit. Double-labeled neurons were found in five cases in which the pairs of deposits were separated by distances of $600 \mu \mathrm{m}$ or less.

When matched with the $\mathrm{CO}$-stained sections, retrogradely labeled neurons in either VPM or VPL appeared in both the COrich and $\mathrm{CO}$-weak compartments of the nuclei (Figs. 4-6) (Rausell and Jones, 1991a; Rausell et al., 1992). The majority of the retrogradely labeled neurons were especially concentrated in the CO-rich compartments. In the CO-rich compartments, large Nissl-stained neurons normally tend to cluster in groups of about $50-70$ cells, separated by spaces of variable size, containing smaller cells that form the matrix compartment of weaker staining in $\mathrm{CO}$ preparations. Most of the retrogradely labeled neurons, when plotted in relation to the Nissl-stained cells, clearly belonged to the neuronal clusters (Figs. 2, 3). The percentage of neurons that were labeled in each cluster depended on the extent of the injection site. The larger the injection the higher the percentage. However, even in the cases with the highest number of retrogradely labeled neurons, only about $60-75 \%$ of the neurons of a cluster were labeled (Figs. 2, 3).

After the smallest injection, a single cluster of neurons was labeled, but in most cases, two or three clusters were labeled. These tended to be aligned anteroposteriorly in VP, best seen in the sagittal reconstructions in Figures 7-10. In VPM, the aligned clusters occupied one or two of the anteroposteriorly oriented CO-dense rod domains. Small injections labeled clusters in a single rod, larger injections labeled clusters in two or more rods.

In VPL, anteroposteriorly aligned clusters of retrogradely labeled neurons occupied parts of the $\mathrm{CO}$ dense sheets or lamellae that extend anteroposteriorly through much of the nucleus. Small injections labeled a line of clusters at one dorsoventral level in a lamella, larger injections labeled lines of clusters at two or more dorsoventral levels (Figs. 7-10, sagittal views).

The degree of intermingling of neurons retrogradely labeled with different dyes in the same cluster and the occurrence of double-labeled neurons depended on the distance separating the two injection sites (Figs. 7-10). Double-labeled neurons and a high degree of intermingling of neurons labeled with different dyes in the same cluster were found in the cases in which the distance between deposits was less than $600 \mu \mathrm{m}$ (Table 1; Figs. $8-10$ ). When the distance between injections was greater than $600 \mu \mathrm{m}$, no double-labeled neurons were found, and the degree of intermingling of cells labeled with different dyes in the same cluster was reduced (Figs. 7, 9). In cases in which the pairs of deposits were separated by $1310 \mu \mathrm{m}$ or more, neurons retrogradely labeled with FB or DY tended to be concentrated in separate but neighboring clusters. However, even in cases with the largest separations (ca. $1.5 \mathrm{~mm}$ ) between the injection sites, clusters of neurons mainly labeled by FB or DY always con-

$\leftarrow$

Figure I, A, Fluorescence photomicrograph, showing locations and extent of deposits of Diamidino yellow $(D Y)$ and Fast blue $(F B)$ in tracks left by tungsten microelectrodes used to record receptive field data on neurons located in the foot representation of area $3 \mathrm{~b}$. $B$, Photomicrograph from the Nissl-stained section adjacent to $A$, showing the electrode track (arrows) and the granular architecture typical of area $3 \mathrm{~b}$. $C$, Fluorescence photomicrograph from another brain showing a second pair of DY and FB injections in area $3 \mathrm{~b}$. D. Fluorescence photomicrograph from VPM showing characteristic cytoplasmic labeling of cells retrogradely labeled with FB and nuclear labeling of cells labeled with DY. Double-labeled cells $(D L)$ show both nuclear and cytoplasmic labeling. $E$ and $F$, Sites of paired injections at the lateral $(E)$ and medial $(F)$ ends of the postcentral gyrus. Thicker lines indicate central $(C S)$, intraparietal $(I P)$, lateral $(L)$, and inferior precentral sulei $(I P C)$ and medial border of hemisphere. Interrupted lines indicate borders of area $3 \mathrm{~b}$. Insets indicate representation patterns around the ends of the central sulcus in Macaca mulatta. Dots, FB; asterisks, DY. Scale bars: $A-C, 500 \mu \mathrm{m} ; D, 25 \mu \mathrm{m} ; E$ and $F, 1 \mathrm{~mm}$. 
A

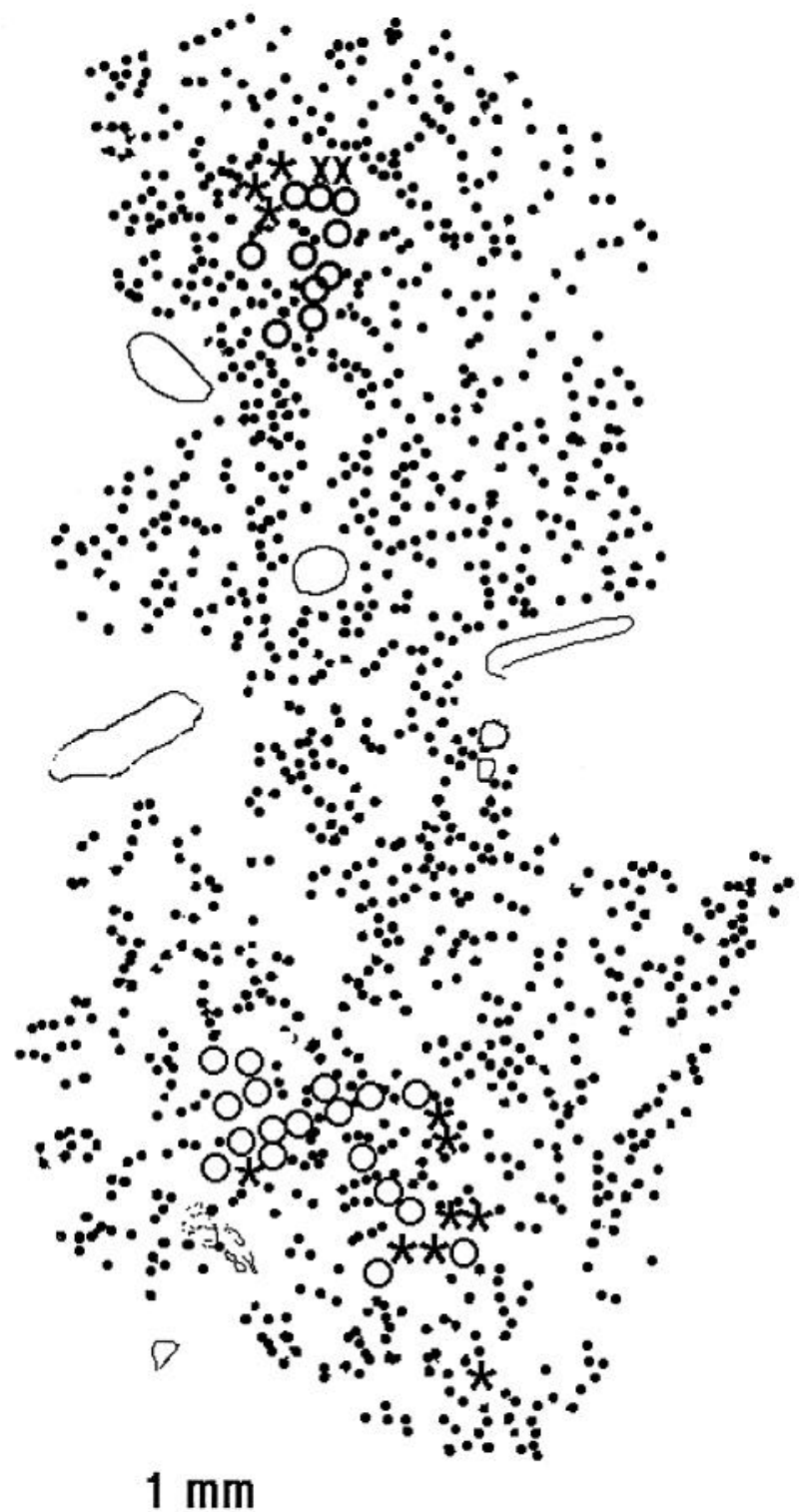

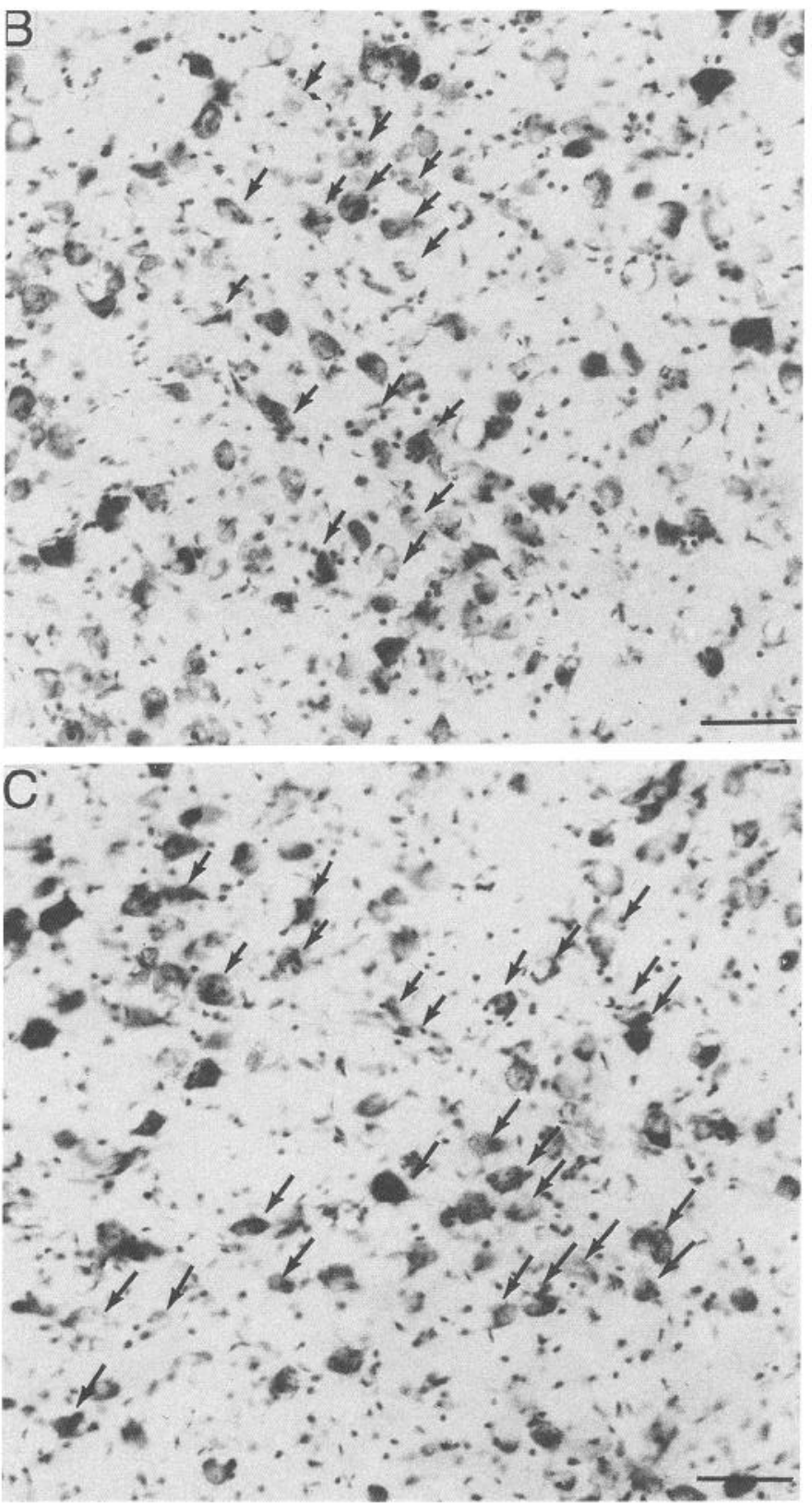

Figure 2. A,Computer-superimposed plots showing all Nissl-stained cells (dots) in a region of retrograde labeling in VPM and the labeling of cells with FB (circles) or DY (crosses), or with both dyes (stars), in two clusters. $B$ and $C$, Photomicrographs of the upper (B) and lower $(C)$ regions of labeled cells shown in $A$, made from the section that was stained with thionin subsequent to plotting the labeled cells under the fluorescence microscope. Arrows indicate the previously retrogradely labeled cells as marked by symbols in $A$. Scale bars, $100 \mu \mathrm{m}$.

tained some neurons labeled with the seemingly inappropriate dye. These points are fully documented below in which cases are described in order of decreasing distance between the paired dye deposits.

\section{Specific details of representative cases with retrograde labeling in VPM}

$52 R$ (Figs. 4, 7). The fluorochromes were deposited in area $3 \mathrm{~b}$ at the lateral end of the central sulcus. FB was pushed into an electrode track in which neurons had been driven by stimulation of a receptive field on the zygomatic region of the face and DY into a track $1 \mathrm{~mm}$ lateral to the first in which neurons had been driven by stimulation of a receptive field on the upper lip. The distance between the cores of the deposits, when measured in the histological sections was $1500 \mu \mathrm{m}$ due to different inclinations of the tips of the pipettes. No double-labeled neurons were found. The FB injection was very small and produced a small number of retrogradely labeled neurons (Table 2) that were located anteriorly in VPM. The DY injection was larger, and labeled neurons were found over a greater anteroposterior extent measuring $850 \mu \mathrm{m}$. When matched to the CO sections, the FB cells were found to occupy one of the rod-like domains of $\mathrm{CO}$ staining characteristic of VPM, and the DY cells occupied this and three others. The rods were all located in the vertical part of the L-shaped VPM (Fig. 4, left). An anterior and medial rod containing FB- and DY-labeled neurons extended anteroposte- 


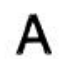

A

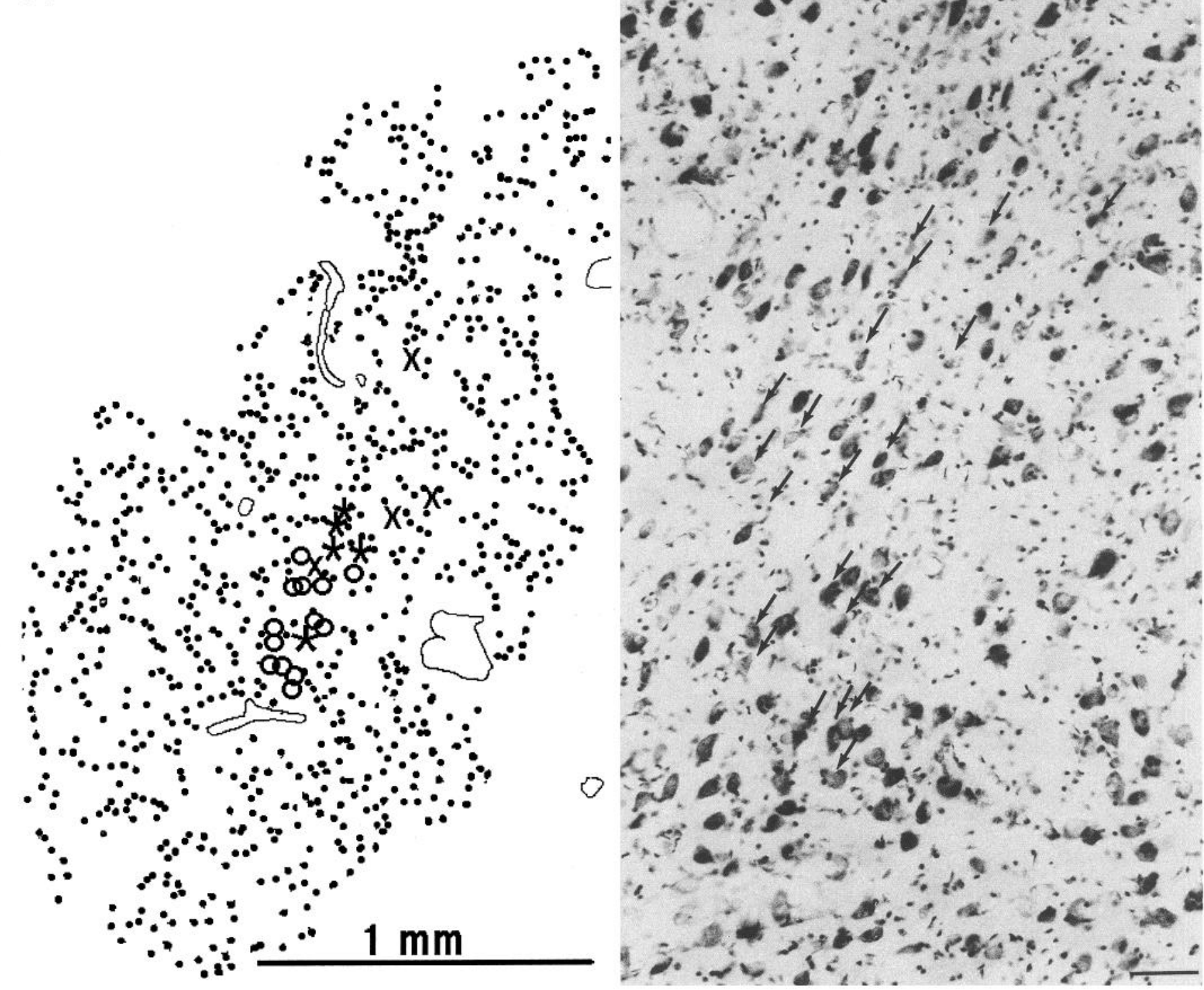

Figure 3. A,Computer-superimposed plots showing all Nissl-stained cells (dots) in a region of retrograde labeling in VPL and the labeling of cells with FB (crosses), DY (circles), or with both dyes (stars), mainly in a single cluster. B. Photomicrograph of the region of labeled cells shown in $A$, made from the section that had been stained with thionin subsequent to plotting the labeled cells under the fluorescence microscope. Arrows indicate the previously labeled cells marked by symbols in $A$. Scale bar, $100 \mu \mathrm{m}$.

riorly for about $300 \mu \mathrm{m}$. FB- and DY-labeled neurons tended to be located in neighboring but separate clusters of cells (Fig. 7), and clusters of FB-labeled cells were always located medial to clusters of DY-labeled cells (Fig. 7). The separation between the FB and DY clusters was about $150 \mu \mathrm{m}$. However, occasionally some FB-labeled neurons were found within a DY cluster, and some DY neurons within a FB cluster. A second rod, containing several clusters of DY-labeled neurons only, was found ventral and lateral to the first and extended anteroposteriorly for about $400 \mu \mathrm{m}$. Two small satellite rods also contained a few DYlabeled neurons only. These were located posterior, lateral, and ventral to the other rods, and extended anteroposteriorly for about $150 \mu \mathrm{m}$ (Fig. 7). A few DY-labeled neurons were located in the ventral part of the VPM matrix in which CO staining is weak and not organized in rods. Cells in this position are labeled as the result of dye involvement of layer I of the cortex (Rausell and Jones, 1991b).

$45 R$ (not illustrated). Both deposits were located in area $3 \mathrm{~b}$ close to the lateral end of the central sulcus. Receptive field data were not recorded in this case. The distance between the core of the deposits was $1310 \mu \mathrm{m}$. No double-labeled neurons were found in the thalamus. A large number of labeled neurons were found in clusters in VPM over an anteroposterior extent of 1200 $\mu \mathrm{m}$. One ventral and medial CO-stained rod contained most of the DY-labeled clusters, and the immediately adjacent lateral CO-stained rod contained most of the FB-labeled clusters. However, some FB-labeled neurons were found within the DY-labeled clusters, and some DY-labeled neurons within the FBlabeled clusters.

$43 R$ (Figs. 4, 7). Deposits were located in area 3b close to the 

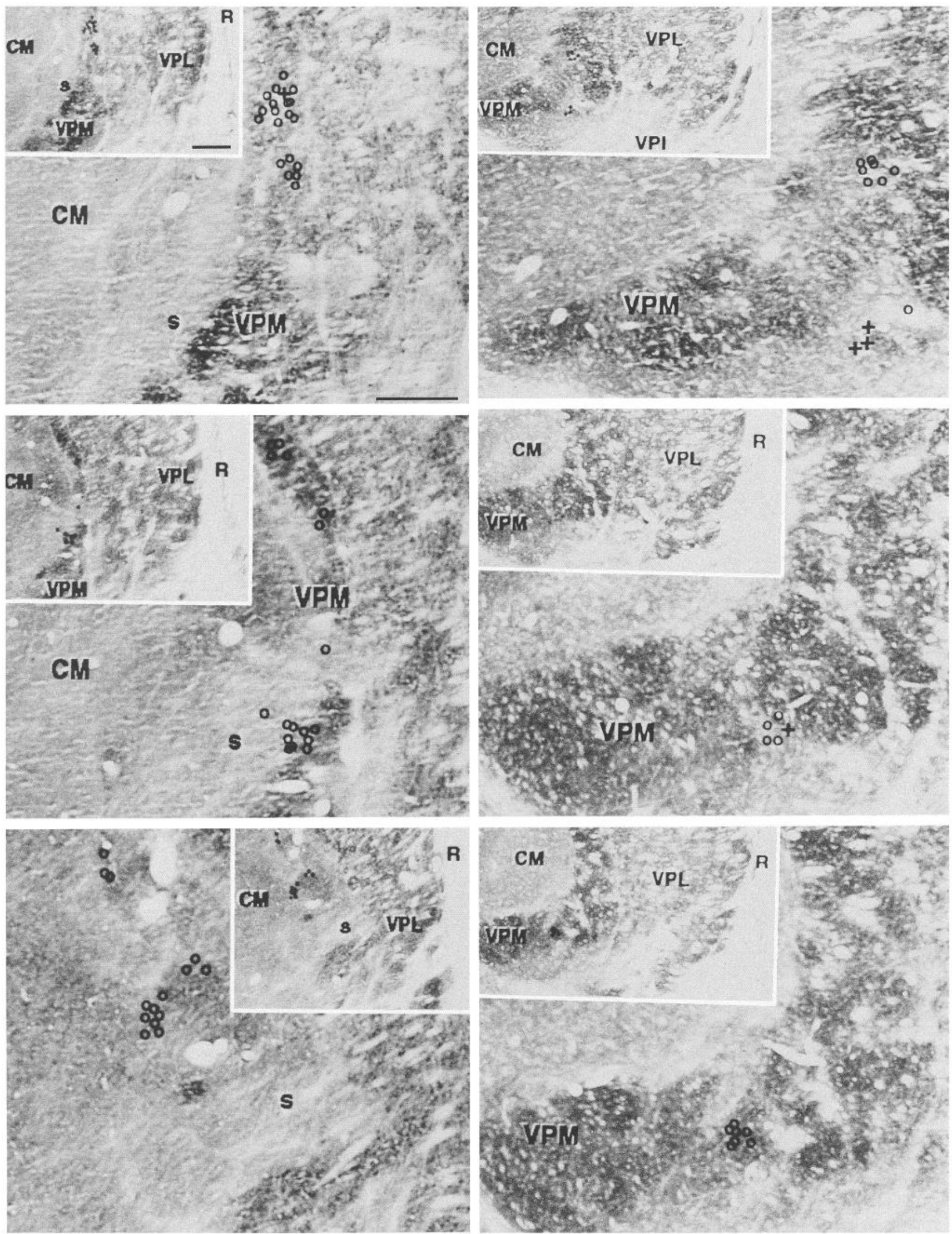

Figure 4. Figures 4-6 are digitized images of portions of the CO-stained frontal sections through VPM or VPL on which have been superimposed the plots of distributions of cells retrogradely labeled with FB (crosses), DY (circles), or with both dyes (dots). In this figure, the left column is from case 52R and the right column from case 43R. They show, from top to bottom, sections in anterior to posterior order. Positions of sections are indicated by arrows on sagittal views in Figures 7-10. Insets indicate positions of labeled regions relative to adjacent nuclei. Scale bars, 1 mm. 

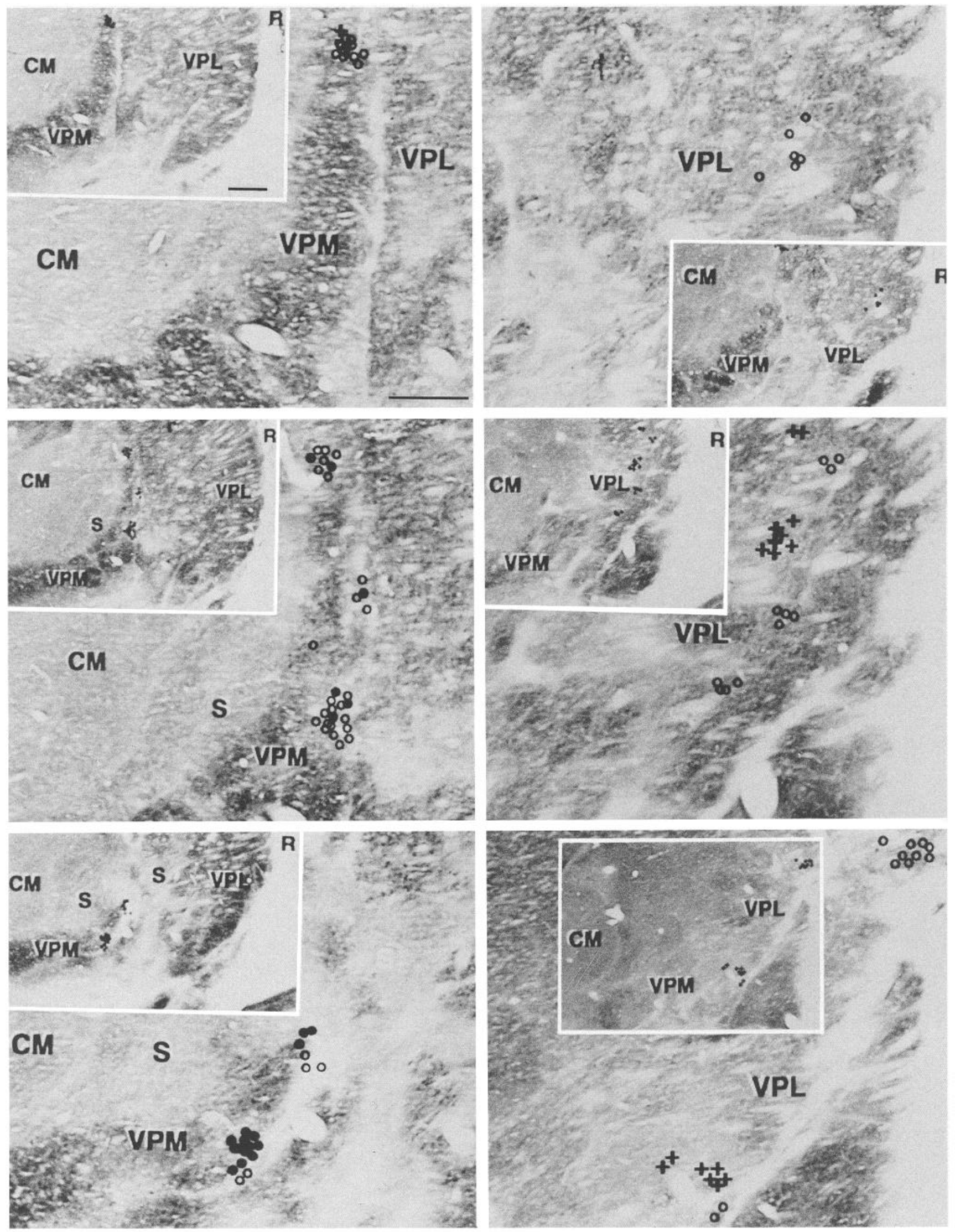

Figure 5. Positions of retrogradely labeled cells in cases 53L (left column) and 52L (right column). Conventions are as in Figure 4. 

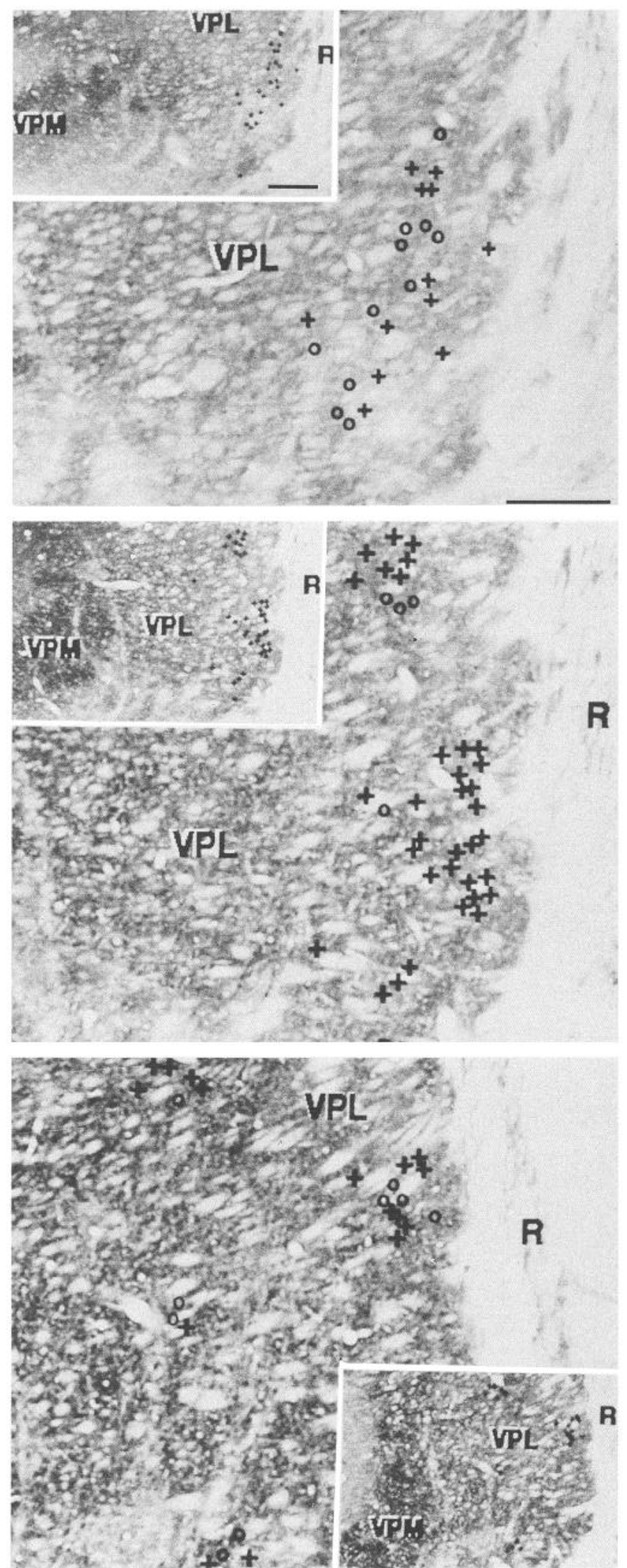
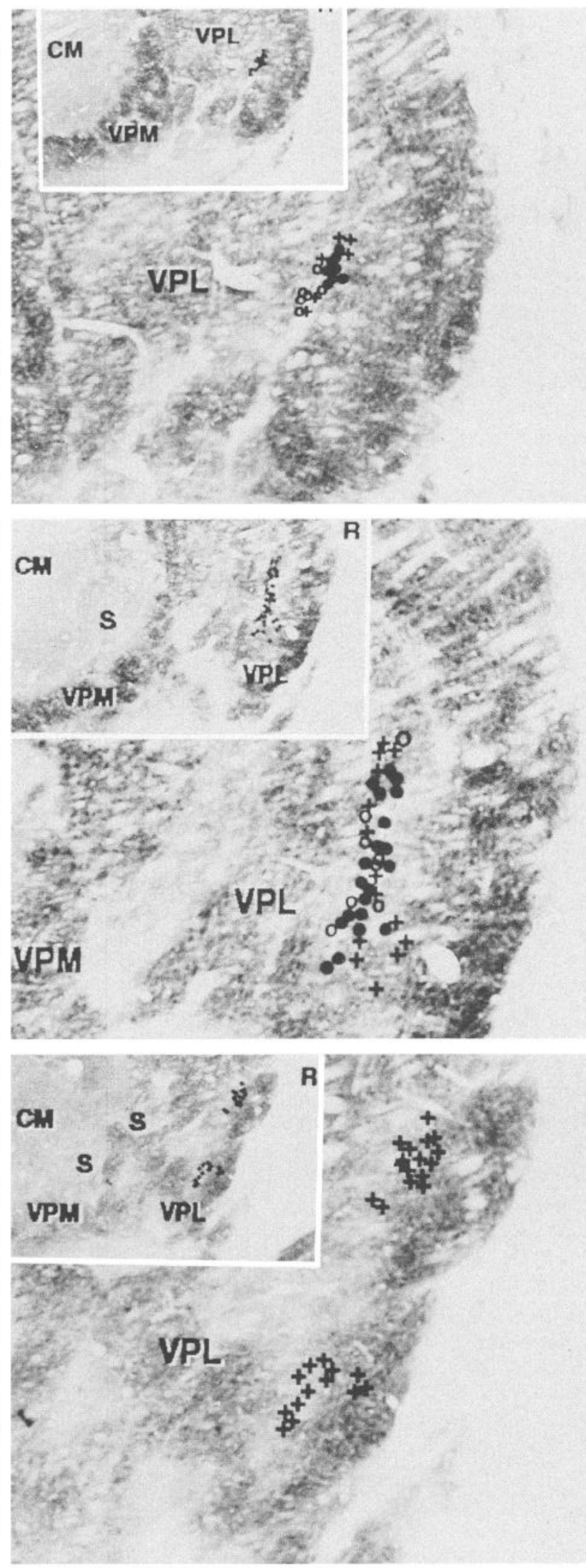

Figure 6. Positions of retrogradely labeled cells in cases 58R (left column) and 53R (right column). Conventions are as in Figure 4. 
lateral end of the central sulcus. No receptive field data were recorded. The distance between the deposits was $1160 \mu \mathrm{m}$. No double-labeled neurons were found in the thalamus (Fig. 7, right). In this case, one $\mathrm{CO}$-stained rod located ventrally, laterally, and anteriorly in VPM contained most of the clusters of FB-labeled neurons (Fig. 4, right). The labeled region extended anteroposteriorly for approximately $300 \mu \mathrm{m}$. This tended to merge with a second rod lying medial to the first, that contained most of the clusters of DY-labeled neurons (Fig. 7) and extended antcropostcriorly for $500 \mu \mathrm{m}$ (Fig. 7). The two rod-like domains of labeled neurons tended to merge posteriorly, at which point few FB-labeled neurons were included in DY clusters, and vice versa. A few FB- or DY-labeled neurons were found outside the main FB- and DY- labeled rods (Fig. 7). A small number of cells labeled with either of the two dyes was found in the medial part of the matrix.

$5 I R$ (Fig. 8). Both deposits were located in area 3b anterior to the lateral end of the central sulcus. $\mathrm{FB}$ was pushed into an electrode track in which neurons had receptive fields on the upper lip and DY into a track $500 \mu \mathrm{m}$ posterior in which neurons had similarly located receptive fields on the upper lip. The tips of the pipettes entered at different inclinations, so that the actual distance between the cores became $280 \mu \mathrm{m}$. FB-, DY-, and double-labeled neurons were found in the vertical part of VPM (Table 2). They occupied zones that were included in two COstained rods. $\Lambda$ dorsally located rod (Fig. 8, left) contained clusters of FB-, DY-, and double-labeled neurons. In the most anterior $100 \mu \mathrm{m}$, labeled clusters contained predominately DY-labeled neurons. These clusters also contained many FBlabeled neurons as well as a significant number of double-labeled neurons. Over the next $250 \mu \mathrm{m}$, labeled clusters contained predominately FB-labeled neurons. These also contained a considerable number of DY-labeled cells, and at the merging point, many double-labeled neurons were found. Labeled cells were also found in a second CO-stained rod, located about $1500 \mu \mathrm{m}$ ventral to the first and in the lateral aspect of the horizontal part of VPM. This commenced approximately $500 \mu \mathrm{m}$ posterior to the beginning of the first rod of labeled cells (Fig. 8). Anteriorly, this second rod contained clusters of mainly DY-labeled cells among which some FB-labeled and double-labeled cells were also found. More posteriorly, clusters of mainly FB-labeled cells appeared, and extended for another 150-200 $\mu \mathrm{m}$. At the merging point, clusters of labeled cells contained both DY- and FB-labeled neurons, and many were double labeled. In spite of the high degree of intermingling, FB-labeled clusters tended to be located medial to DY-labeled clusters. Some FB-, DY-, and double-labeled cells were observed in the medial VPM matrix.

$53 L$ (Figs. 5, 8). Both fluorochrome deposits were located in area $3 \mathrm{~b}$ at the lateral end of the central sulcus. FB was pushed into an electrode track in which neurons had receptive fields on the upper lip and DY into a track $500 \mu \mathrm{m}$ medial to the first in which neurons also had receptive fields on the same part of the upper lip. The inclination of the tips of the micropipettes resulted in a separation of the cores of the injections measuring $250 \mu \mathrm{m}$. FB-, DY-, and double-labeled neurons were found in the vertical part of VPM. Two principal regions equivalent to two COstained rods contained labeled neurons, with two satellite regions of fewer labeled cells surrounding them (Fig. 5, left). The more anterior and dorsal rod of labeled cells extended anteroposteriorly for $400 \mu \mathrm{m}$, and contained a large number of double-labeled neurons, especially at posterior levels (Fig. 8, right). DY, FB, and double-labeled neurons coexisted in the same clusters of labeled cells. The second rod began $300 \mu \mathrm{m}$ posterior to the commencement of the first rod, and was located $2 \mathrm{~mm}$ more ventrally. It also contained large numbers of FB-, DY-, and double-labeled cells. The two satellite regions also contained FB-, DY-, and double-labeled neurons. There was a tendency for a greater number of FB-labeled neurons to be located posteriorly (Fig. 8). FB-, DY-, and double-labeled neurons were also found in the medial VPM matrix.

\section{Specific details of cases with retrograde labeling in VPL}

$52 L$ (Figs. 5, 9). Both fluorochrome deposits were located in area $3 \mathrm{~b}$ near the medial end of the central sulcus. FB was pushed into an electrode track in which neurons had receptive fields on the skin of the medial inguinal region. DY was pushed into a track $1000 \mu \mathrm{m}$ lateral to this, in which the neurons had receptive fields extending over the medial and lateral inguinal region. In the sections, the distance between the cores of the deposits was $1100 \mu \mathrm{m}$. Neurons retrogradely labeled with FB or DY were found in the lateral aspect of VPL. No double-labeled neurons were found. All labeled neurons were clustered but, collectively, the clusters formed a single lamella-like arrangement located anteriorly in VPL (Fig. 5, right). A ventrally located set of clusters of DY-labeled cells extended anteroposteriorly for about 500 $\mu \mathrm{m}$. Two hundred microns posterior to the commencement of this set of clusters, second, and third sets of clusters of DYlabeled cells appeared $1 \mathrm{~mm}$ ventral and $1 \mathrm{~mm}$ dorsal to the first set. These extended posteriorly for another $600 \mu \mathrm{m}$ (Fig. 9, left). Most of the neurons in the anterior $200 \mu \mathrm{m}$ of the three sets of clusters were DY labeled, but occasional FB-labeled neurons were intermingled. More posteriorly, clusters of FB-labeled cells appeared and usually lay slightly medial and dorsal to the clusters of DY-labeled cells (Fig. 9), although some FB-labeled neurons were invariably found in a DY cluster, and vice versa. When compared with the distribution of CO-stained densities found in the same section, most of the labeled neurons occupied a continuous, CO-rich lamella, in the lateral part of VPL. However, posteriorly, the ventral set of clusters became displaced laterally into a second adjacent lamella-like zone of dense $\mathrm{CO}$ staining, closer to the external medullary lamina (Figs. 5, 9). As a whole, the region occupied by the total population of labeled neurons was $500 \mu \mathrm{m}$ wide and $800 \mu \mathrm{m}$ long and bifurcated posteriorly into dorsal and ventrolateral parts.

$58 R$ (Figs. 6, 9). The fluorochrome deposits were located in area $3 \mathrm{~b}$ at the medial end of the central sulcus. DY was pushed into an electrode track in which neurons had receptive fields on the contralateral great toe. FB was pushed into a track $500 \mu \mathrm{m}$ medial to this, in which neurons had receptive fields on the lateral plantar digital pad. In the sections, the distance between the cores of the deposits was $600 \mu \mathrm{m}$. Neurons retrogradely labeled with FB or DY were found in the lateral part of VPL, and a certain number were double labeled (Fig. 9, right). Anteriorly, a first set of clusters of labeled neurons was found in the ventral and lateral part of VPL, along the external medullary lamina (Fig. 6, right). In these, FB- and DY- labeled neurons were mixed in the same cluster, and double-labeled neurons were infrequent, except posteriorly. The number of FB- and DY-labeled neurons increased substantially after the first $400 \mu \mathrm{m}$, and extended anteroposteriorly for a further $2600 \mu \mathrm{m}$ within VPL (Fig. 9). There, they formed two small rows located ventrally and dorsomedially and tending to merge (Fig. 9). Approximately $1600 \mu \mathrm{m}$ from the commencement of the first set of clusters of labeled neurons, a large second set of clusters of labeled neurons 

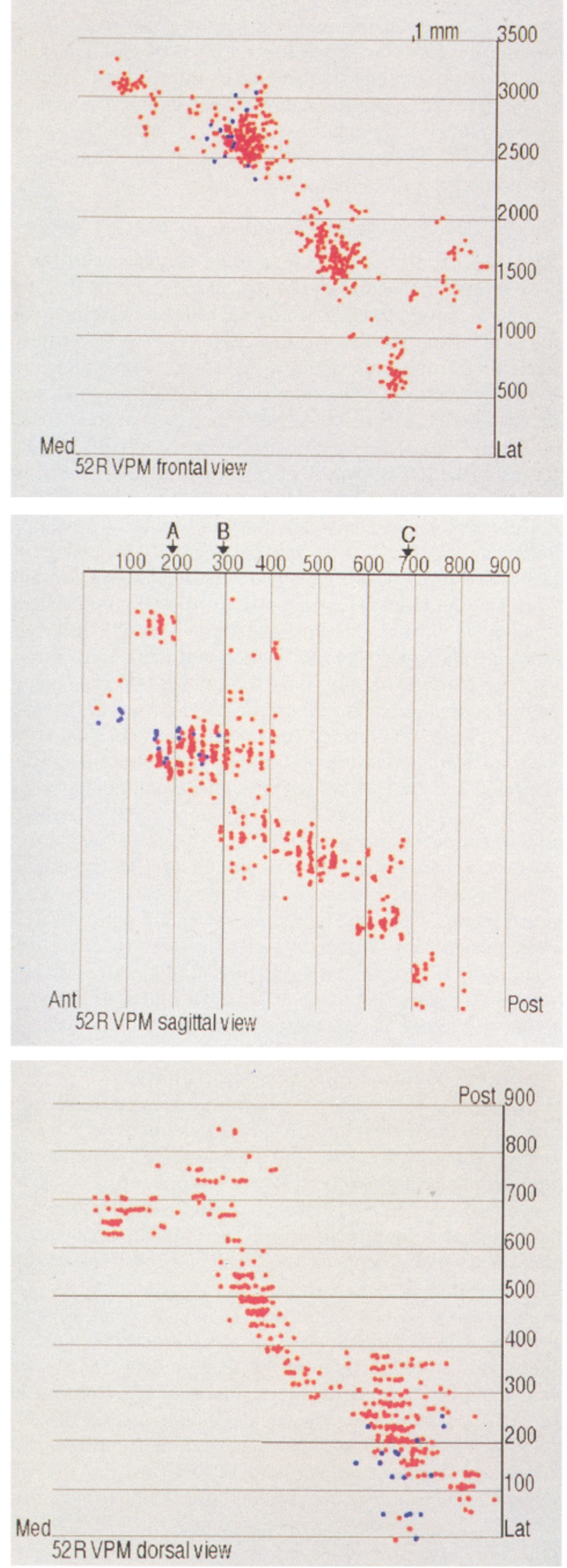
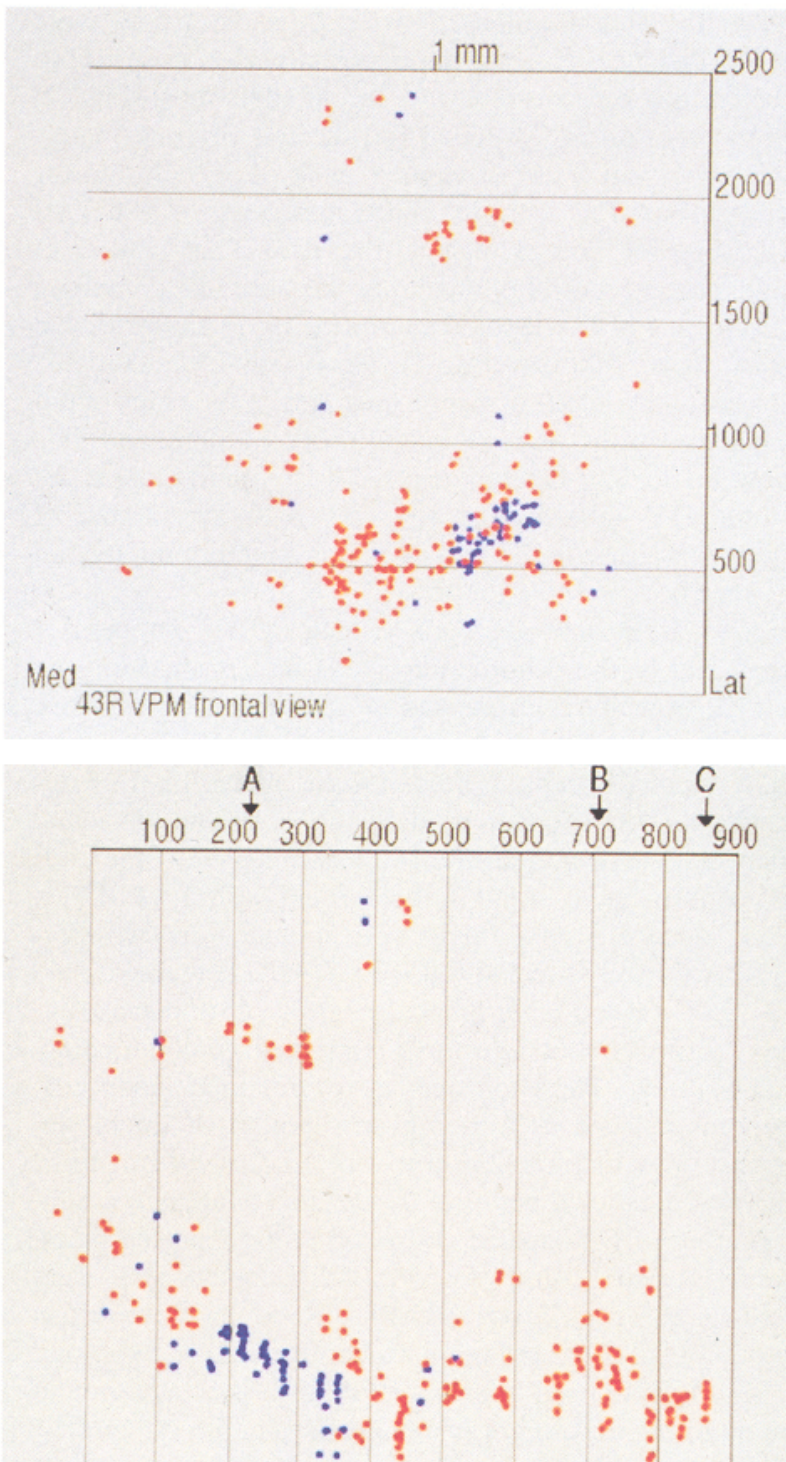

Ant

43R VPM saaittal view

Post

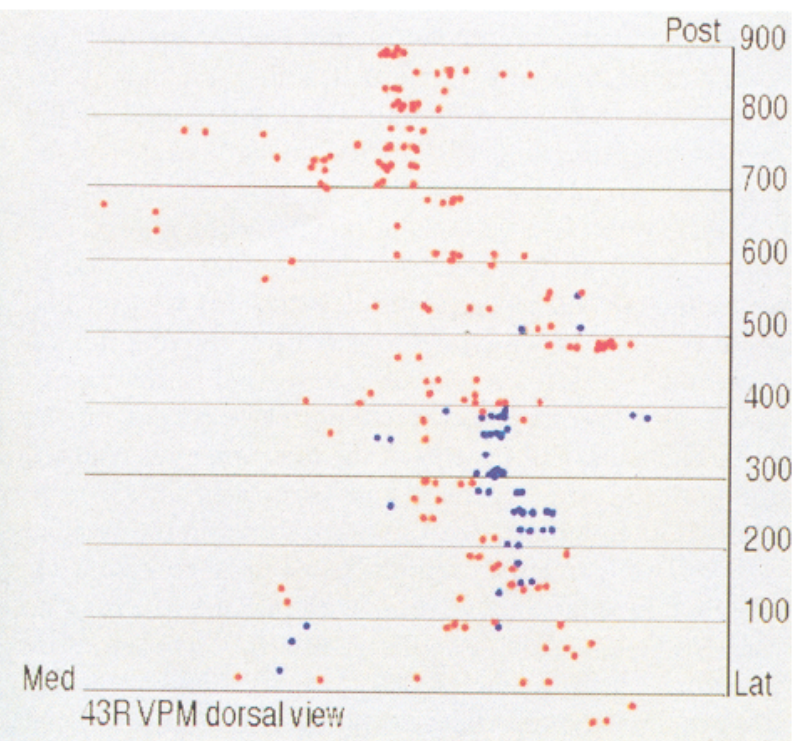


appeared. This was located about $1 \mathrm{~mm}$ medial, and about $1 \mathrm{~mm}$ ventral to the first set. Like the first set, this second set of clusters consisted of a moderate number of DY- and FB-labeled neurons that were usually intermingled in the same clusters, with very few double-labeled neurons. However, $400 \mu \mathrm{m}$ more posteriorly the total number of labeled cells increased significantly and the number of double-labeled cells also increased and became especially high at posterior levels. As in the first set of clusters, some clusters of labeled cells were separated from one another by as much as $1 \mathrm{~mm}$, hut overall they gradually merged to form a lamina of labeled cells that moved dorsally on being traced posteriorly (Fig. 9). Two additional small sets of clusters of FBand DY-labeled cells with very few double-labeled neurons were found $2 \mathrm{~mm}$ medial and dorsal to the main zone of labeling in VPL (Fig. 9). The FB- and DY-labeled neurons were not located in any particular position with respect to one another in any of the labeled clusters.

When the location of the labeled neurons was compared with the locations of the $\mathrm{CO}$-stained densities in the same sections, most of the clusters of labeled neurons were located within two continuous CO-rich VPL lamellae, close to the external medullary lamina. The medially placed cells occupied different lamellae. Some DY-, FB-, and double-labeled neurons were also found in CO-wcak matrix regions of VPL, in the spaces intervening between the CO-rich lamellae. These are probably labeled by dye involvement of layer I of the cortex (Rausell et al., 1992).

$53 R$ (Figs. 6, 10). The fluorochrome deposits were located in area $3 b$ near the medial end of the central sulcus, close to its posterior lip. DY was pushed into an electrode track, made from an anteroposterior inclination, in which neurons had receptive fields on the medial aspect of the knee. FB was pushed into a similarly oriented track, $500 \mu \mathrm{m}$ posterior to the first, in which neurons had receptive fields on the identical region. The FB deposit was significantly larger than the DY deposit. In the sections, the distance between the cores of the deposits was 300 $\mu \mathrm{m}$. FB-, DY-, and double-labeled neurons were located in a single set of clusters in the lateral aspect of VPL (Fig. 6, right). The zone of labeled clusters was located in the middle of the anteroposterior extent of VPL, and its total anteroposterior length was about $1200 \mu \mathrm{m}$ (Fig. 10, left). The dorsoventral extent was about $1500 \mu \mathrm{m}$. In the labeled clusters situated more anteriorly, DY-, FB-, and double-labeled neurons were intermingled (Fig. 10). The posterior $200 \mu \mathrm{m}$ of the total zone of labeled clusters was formed by one ventral and one dorsal cluster, each consisting of only FB-labeled cells, and separated by $1000 \mu \mathrm{m}$ (Fig. 10).

When the location of the labeled neurons was compared with the location of the CO-stained densities found in the same section, all labeled neurons were located in the same CO-rich lamella. Some labeled neurons were located in the CO-weak matrix region intervening between this and the immediately adjoining lamella.
$51 L$ (Fig. 10). The fluorochrome deposits were located in area $3 \mathrm{~b}$ near the medial end of the central sulcus. FB was pushed into an electrode track at the posterior lip of the sulcus in which neurons had receptive fields in the lateral aspect of the contralateral lower leg. DY was pushed into a track $350 \mu \mathrm{m}$ posteromedial to the first in which neurons had receptive fields on the same region. The FB deposit was significantly larger than the DY deposit. In the sections, the distance between the cores of the deposits was $100 \mu \mathrm{m}$. Cells retrogradely labeled with FB or DY were found in the middle of the anteroposterior extent of VPL. Almost all neurons were double labeled. One set of clusters of labeled neurons extended anteroposteriorly for $650 \mu \mathrm{m}$ (Fig. 10, right). Two hundred micrometers before the end of this set, a second set of clusters of labeled neurons appeared slightly medial and ventral to the first (Fig. 10). On comparing the location of the labeled neurons with the location of the $\mathrm{CO}$-rich densities, all the labeled neurons were contained in the same CO-rich lamella. Double-labeled neurons were also found in the adjacent $\mathrm{CO}$-weak matrix.

\section{Analysis of the percentages of double-labeled neurons}

Table 2 shows the relative and absolute numbers of double-labeled neurons in the nine cases. Double-labeled neurons were found in five of the cases. The relative and absolute numbers of double-labeled neurons decreased as the separation between the cortical deposits increased. This can also be seen in Figure 11, in which the average of the percentage of double-labeled neurons found among the total population labeled with each dye in the five cases is plotted against the distance between the dual cortical deposits. In these cases, the intracortical extent of the terminal arborizations of the double-labeled neurons would have had to be at least as large as the separation between the two dyes for the neurons to be doubled labeled. The probability $(Q)$ of finding a double-labeled neuron, out of the total population of labeled neurons, is a function of the distance between the injection sites in the cortex $(D)$ and the extent of the arborization of a single thalamocortical axon $(A)$. This assumes that the arbor is radially symmetric and that the dye can be taken up anywhere within the arbor area. Since the injections were placed randomly in relation to the position of the arbors, the probability of either dye deposit occurring within a given arbor is proportional to $A$ $+D$. The probability of both dye deposits occurring within a given arbor is proportional to $A-D$. Therefore,

$$
Q=(A-D) /(A+D) \text {. }
$$

When $Q$ is plotted against $D$, this equation describes a curved line, the concavity of which is determined by $A$. The continuous line in Figure 11 is the best fit of this equation to the experimental data points with the constraint that for $D=0$ (two dye deposits overlapping), $Q=1$ (all cells double labeled). The best fit was achieved with $A=550 \mu \mathrm{m}$, which therefore represents the average extent of a single thalamocortical axon arbor, in a direction parallel to the axis passing through the two injection

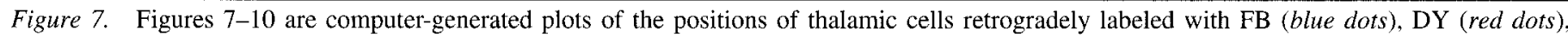

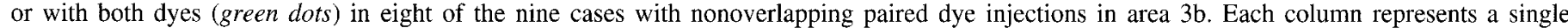

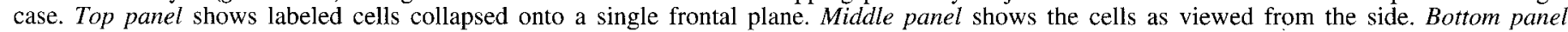

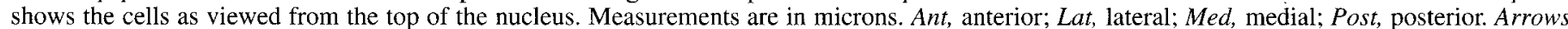

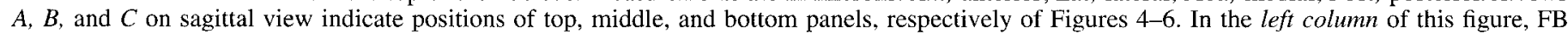

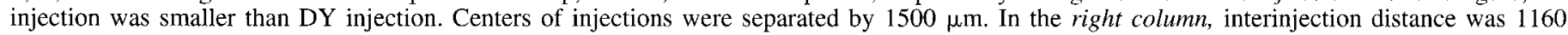
$\mu \mathrm{m}$. There were no double-labeled cells in either case, but single-labeled cells are commingled. 

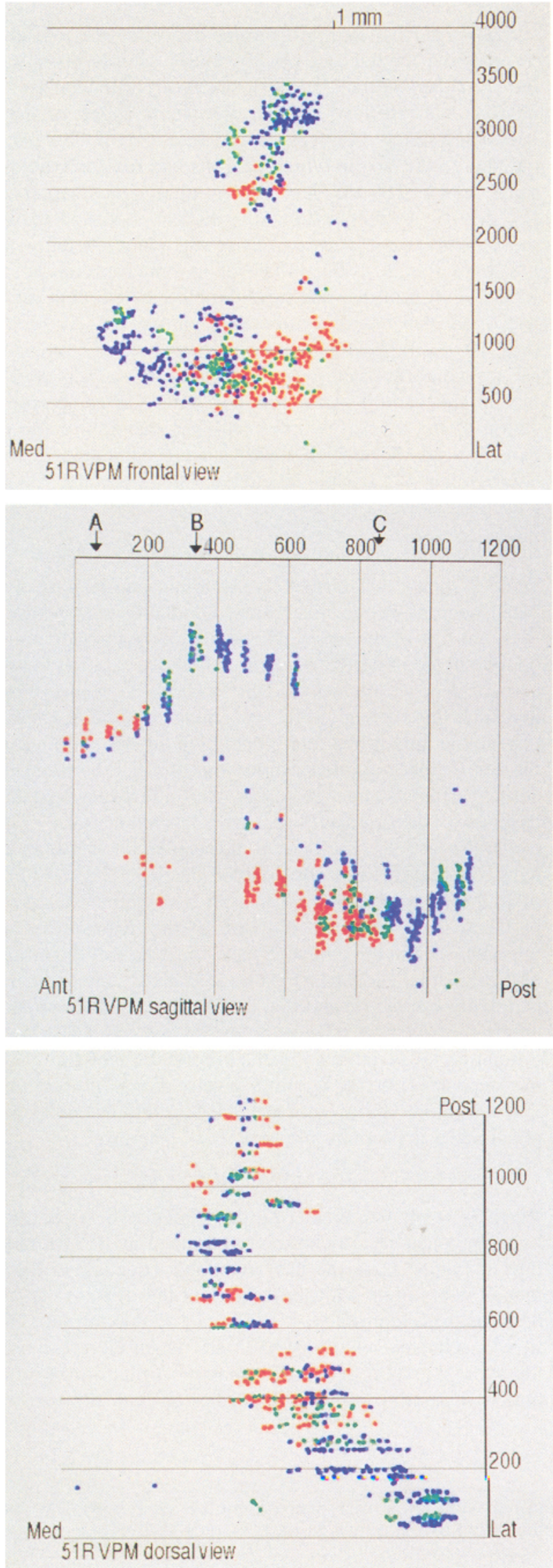

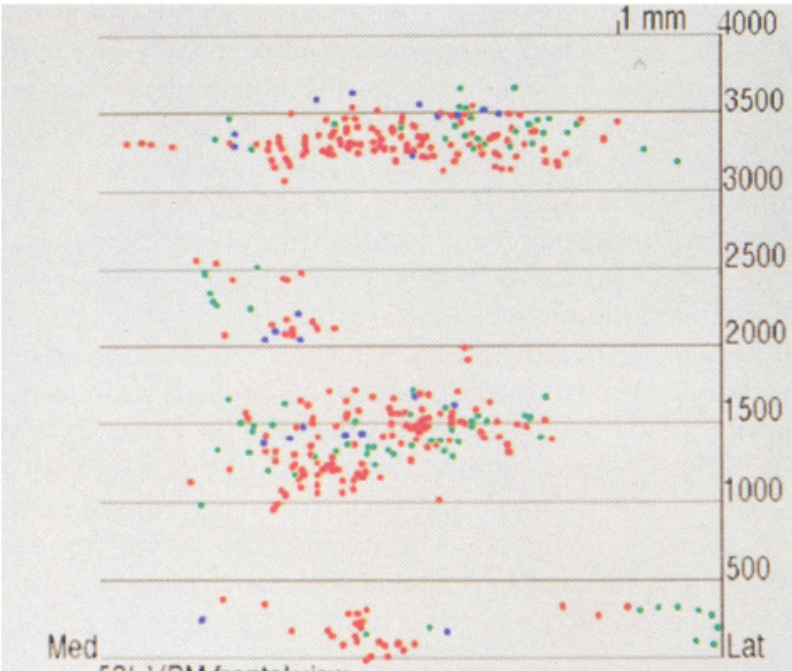

53 L VPM frontal view
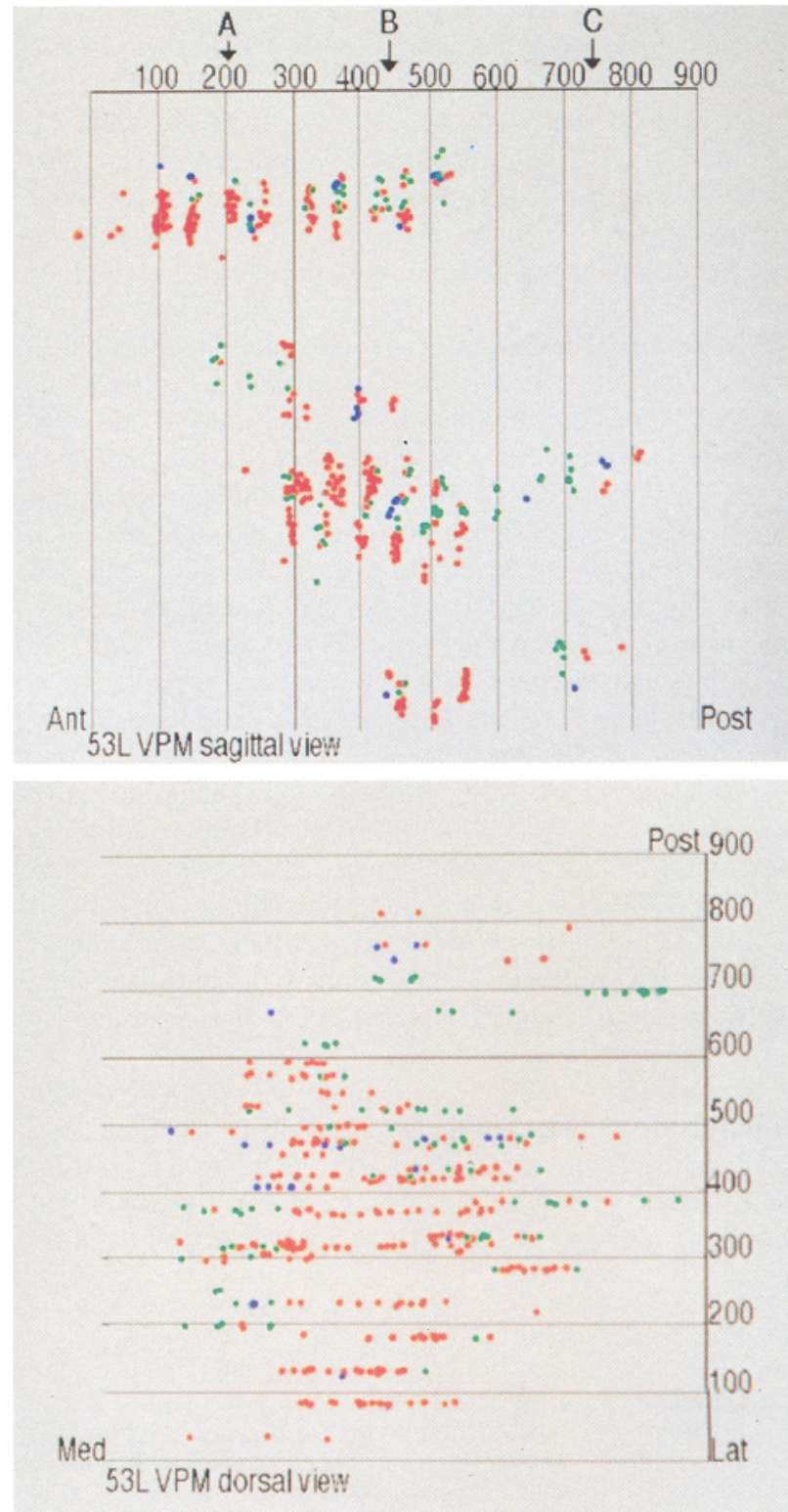

Figure 8. In these cases, interinjection distances were $280 \mu \mathrm{m}$ (left column) and $250 \mu \mathrm{m}$ (right column). Double-labeled cells now start to appear, but many single-labeled cells are commingled. Conventions are as in Figure 7. 

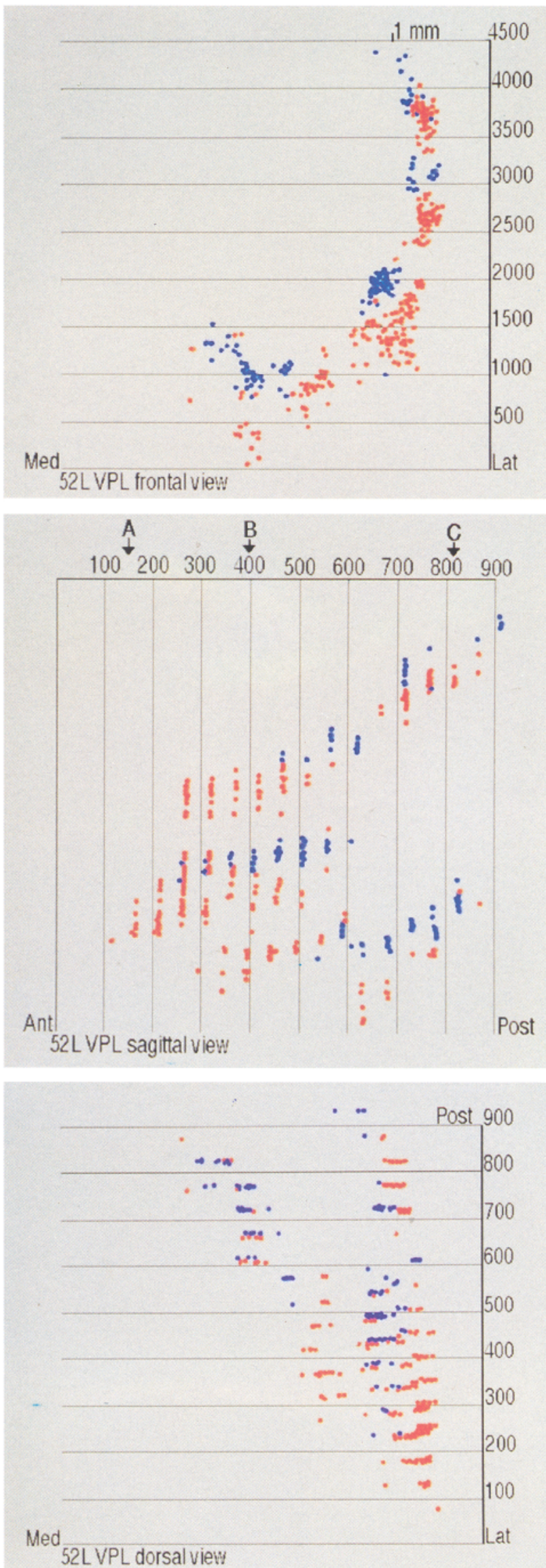
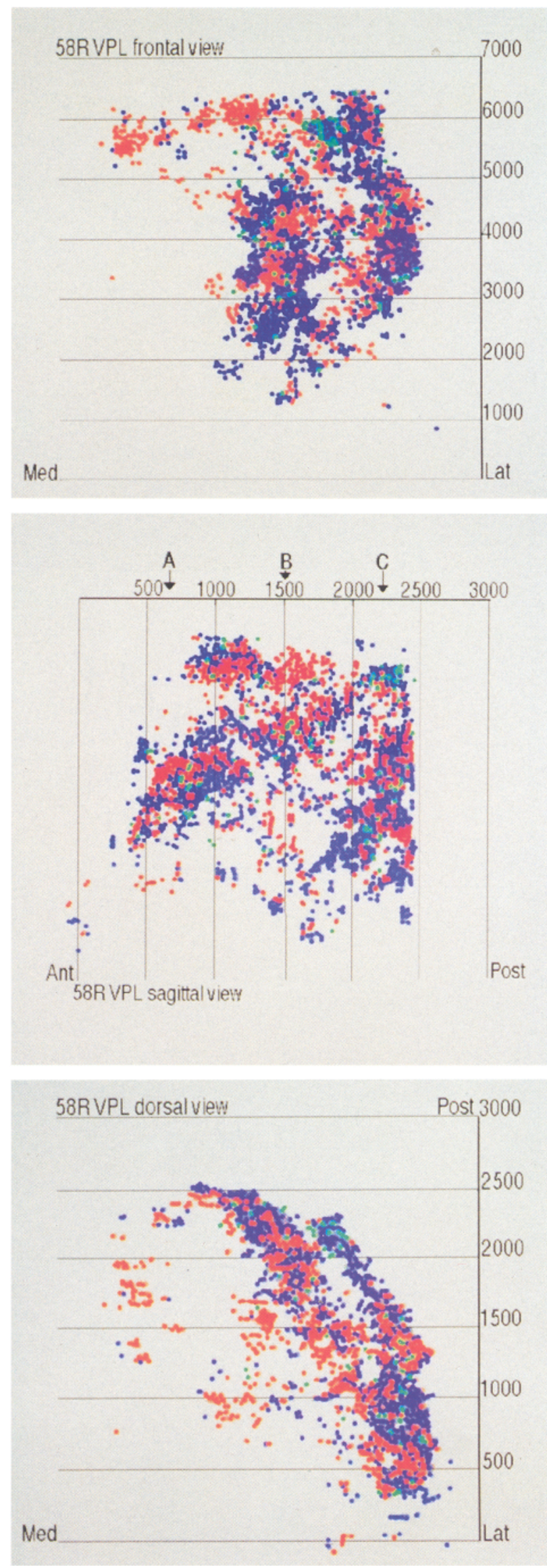

Figure 9. In these cases, interinjection distances were $1100 \mu \mathrm{m}$ (left column) and $600 \mu \mathrm{m}$ (right column). Single-labeled cells are commingled, but double-labeled cells appear only in the right column. Same conventions as Figure 7. 

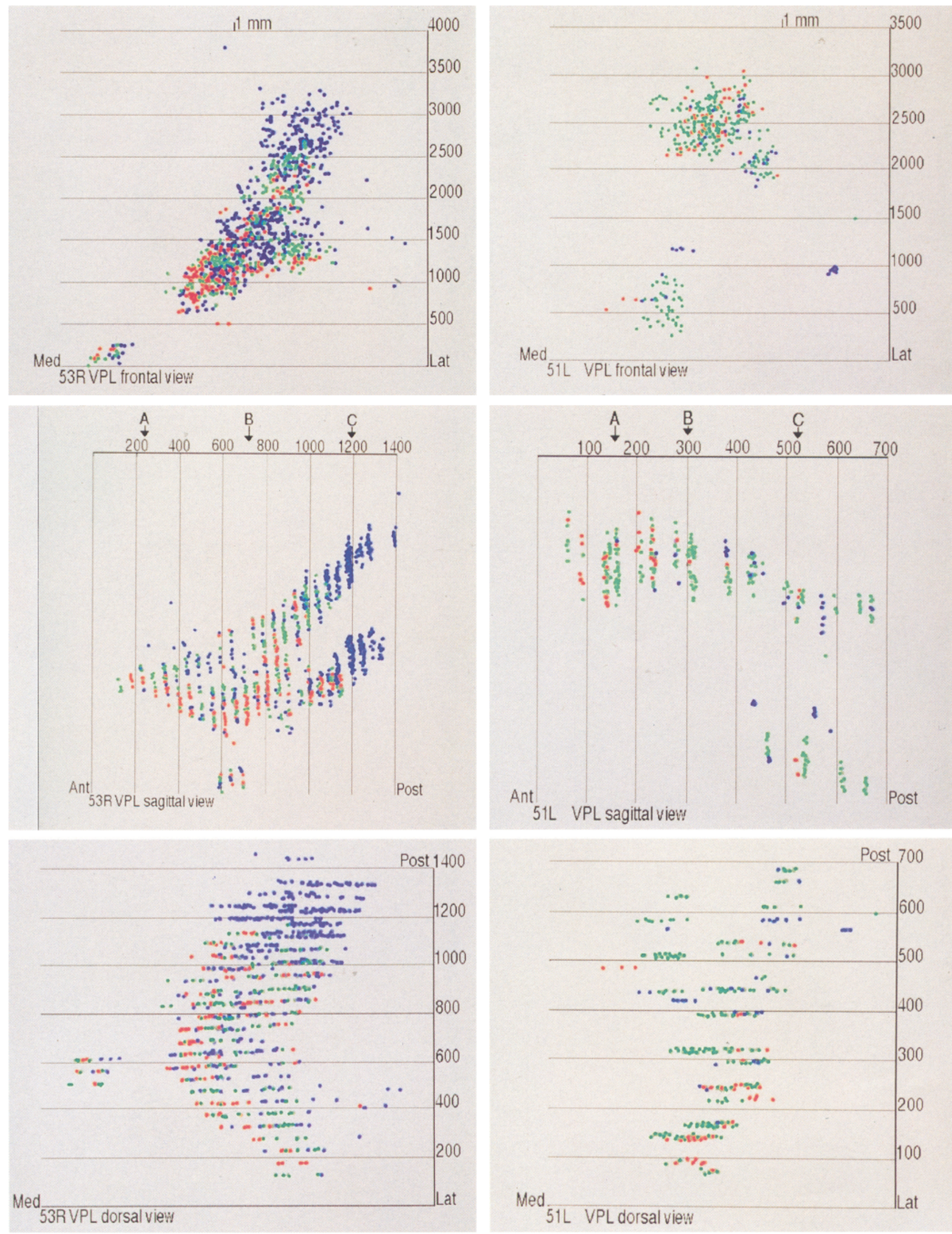

Figure 10. In these cases, interinjection distances were $300 \mu \mathrm{m}$ (left column) and $100 \mu \mathrm{m}$ (right column). Single-labeled cells commingle in the left column, and many cells are double labeled. In the right column, most are double labeled. Same conventions as Figure 7. 


\begin{tabular}{|c|c|c|c|c|c|}
\hline $\begin{array}{l}\text { Case } \\
\text { number }\end{array}$ & $\begin{array}{l}\text { Interinjection } \\
\text { distance }(\mu \mathrm{m})\end{array}$ & $\begin{array}{l}\text { Total labeled } \\
\text { neurons }\end{array}$ & FB neurons & DY neurons & $\begin{array}{l}\text { Double-labeled } \\
\text { neurons }\end{array}$ \\
\hline $51 \mathrm{~L}$ & 100 & 343 & $46(13.4 \%)$ & $51(14.9 \%)$ & $146(71.7 \%)$ \\
\hline $53 \mathrm{~L}$ & 250 & 376 & $23(6.1 \%)$ & $266(70.7 \%)$ & $87(23.1 \%)$ \\
\hline $51 \mathrm{R}$ & 280 & 594 & $279(46.9 \%)$ & $184(30.9 \%)$ & $131(22.1 \%)$ \\
\hline $53 \mathrm{R}$ & 300 & 878 & $505(57.5 \%)$ & $150(17.1 \%)$ & $223(25.4 \%)$ \\
\hline $58 \mathrm{R}$ & 600 & 3935 & $2298(58.4 \%)$ & $1371(34.8 \%)$ & $266(6.8 \%)$ \\
\hline $52 \mathrm{~L}$ & 1100 & 350 & $113(32.3 \%)$ & $237(67.7 \%)$ & 0 \\
\hline $43 \mathrm{R}$ & 1160 & 224 & $56(25.0 \%)$ & $168(75.0 \%)$ & 0 \\
\hline $45 \mathrm{R}$ & 1310 & 209 & $145(69.4 \%)$ & $64(30.6 \%)$ & 0 \\
\hline $52 \mathrm{R}$ & 1500 & 370 & $19(5.1 \%)$ & $351(94.9 \%)$ & 0 \\
\hline
\end{tabular}

sites. The value of $A=550 \mu \mathrm{m}$ is also given by the intersection of the line with the horizontal axis and is close to the figure of $600 \mu \mathrm{m}$ obtained directly from the experimental data as the dye separation distance beyond which no cells were double labeled.

\section{Discussion}

Neurons of the ventral posterior nucleus could only be double labeled by retrograde transport from paired injections of tracer in area $3 b$ when the interinjection distance was less than 600 $\mu \mathrm{m}$. This implies that the extent of intracortical arborization of single thalamocortical axons in area $3 \mathrm{~b}$ is no greater than about $600 \mu \mathrm{m}$. Paired dye injections in are $3 \mathrm{~b}$, separated by up to 1.5 $\mathrm{mm}$, resulted in two overlapping sets of labeled neurons. The degree of overlap was inversely related to interinjection distance

\section{DL vs DYE SEPARATION}

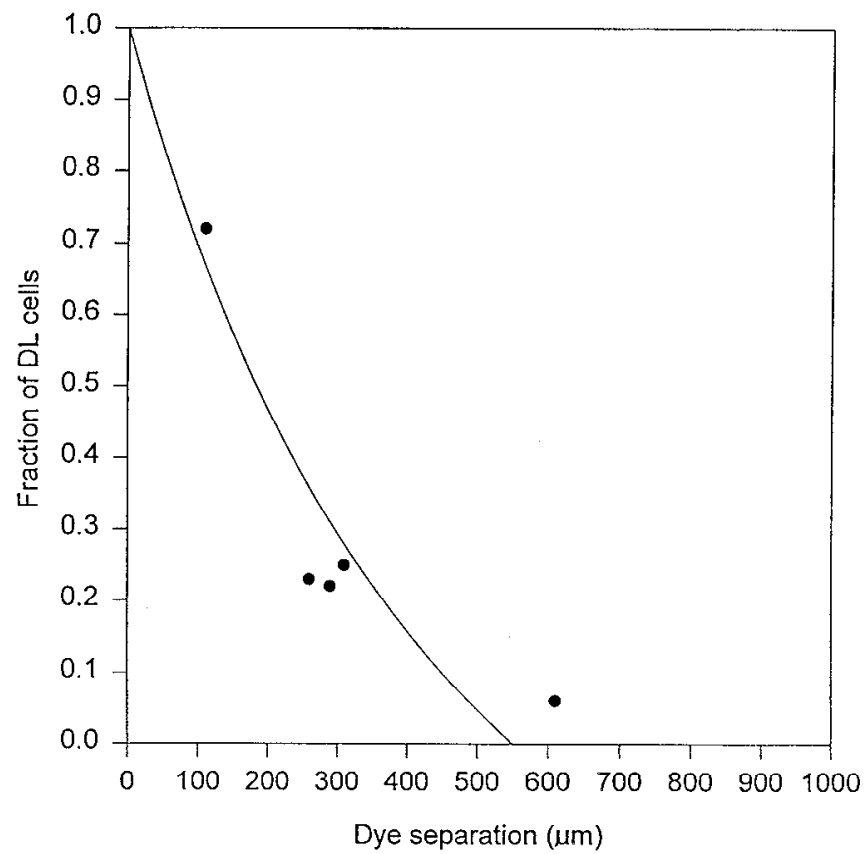

Figure 11. The mean of the percentage of double-labeled cells (ordinate) in the five cases in which double-labeled cells were found (dots), plotted against the distance between the centers of the injections in each case (abscissa). The derived line represents the probability of finding double-labeled cells at a particular interinjection distance. For a probability of 0 (no double-labeled cells), the distance between the centers of the injections must exceed $550 \mu \mathrm{m}$ (see text). and greatest when cortical sites containing neurons with different receptive fields received dye applications. However, in all cases, intermingling of neurons labeled with different dyes was consistently observed. Hence, most neurons of a defined VP cluster project to a corresponding cortical domain in area $3 \mathrm{~b}$, defined in these experiments by the locus of one dye injection, but other cells of the same cluster project to surrounding domains, defined by the locus of the second injection, and thus provide offshoot projections to loci representing the same or different parts of the body surface in area $3 \mathrm{~b}$. The overlap could not be attributed to co-involvement of area 1 in any of the injections.

\section{Interrelation of thalamic and cortical representations}

From the perspective of the cortex, the projection of a representation of a small part of the body from VP to area $3 b$ is formed by axons of neurons located in one set of VP clusters converging on a restricted cortical locus. This cortical locus, however, also receives axons of a few neurons located in nonsomatotopically related VP clusters. Similarly, a number of neurons in the set of clusters primarily related to one cortical locus project to surrounding cortical loci in which neurons have receptive fields on the same or different parts of the body. These loci form the principal cortical targets of other VP clusters.

From the perspective of the thalamus, the cortical projection of a single thalamic cluster is substantially greater than the 550$600 \mu \mathrm{m}$, subtended by the axonal arborizations of its individual cells. 'The projection pattern is one of shifted overlap so that at any locus in VP a majority of the relay neurons will project to onc restricted region of cortex but a significant minority will project to a neighboring region. This receives most of its input from a locus in VP neighboring the first but still containing many neurons projecting to the first region, and so on throughout the nucleus. Although thalamic cells retrogradely labeled from a single injection, were concentrated in one or a few clusters, no injection or pair of injections was sufficiently large to label every cell of a cluster. Although it is likely that some of the unlabeled cells were interneurons (Benson et al., 1991; Hunt et al., 1991), the large size and dense Nissl-staining of many of the unlabeled cells makes it probable that a significant number were relay neurons. These presumably project to cortex outside the dye-injected foci.

\section{Relation to previous investigations}

The aggregation of the majority of the cells projecting to a cortical locus in a concentrated set of clusters in VPL or VPM undoubtedly accounts for the apparent correspondence between 
physiological maps in the ventral posterior nucleus and somatic sensory cortex of macaques (Mountcastle and Henneman, 1952; Poggio and Mountcastle, 1963; Jones and Friedman, 1982; Jones et al., 1982, 1986a,b; Rausell and Jones 1991a) and for the repeated observations of lamellar arrangements of retrogradely labeled cells in VPL after relatively large injections of retrograde tracers in the cortex (Jones et al., 1979; Nelson and Kaas, 1981; Ma and Juliano, 1991), since the clusters are parts of the lamellae.

Previously, it was considered that a narrow rod of cells with the same submodality properties and closely overlapping receptive fields, and extending anteroposteriorly through VPL or VPM, formed a kind of unit of thalamic organization that projected upon one or a small number of focal domains in monkey somatosensory cortex (Jones et al., 1982; Jones, 1985). These domains were approximately $1 \mathrm{~mm}$ in extent and thought to form the basis of functional cortical columns. Application of more sensitive tracers (Darian-Smith et al., 1990; Darian-Smith and Darian-Smith, 1993) showed that larger and more widespread populations of thalamic cells in parts of the VP representation apparently unrelated somatotopically to an injection site, could be retrogradely labeled after relatively small injections. The present results, based upon the smallest feasible cortical injections at physiologically defined sites, indicate that the concept of a unidimensional rod, all members of which project to one or a limited number of cortical columns, is unduly simplified. While it is true that a focal injection of DY or FB tended to label mainly cells concentrated in a single rod-like domain in VPL or VPM, outlying cells, presumably members of other anatomical and functional rods, were also labeled. Moreover, the primary labeled domain invariably contained a significant number of cells retrogradely labeled from an injection of dye into a different, nonsomatotopically related cortical locus, more than $600 \mu \mathrm{m}$ distant from that receiving input from the primary thalamic domain.

It is possible that, physiologically, the offshoot projections from the primary thalamic domain may be weaker and not detected by the multiunit methods customarily used to map representations in somatosensory cortex. More detailed physiological analyses may reveal preexisting thalamocortical projections that escape detection with multiunit methods. In cats, Snow et al. (1988) demonstrated that single thalamic cells with receptive fields on a toe could be antidromically activated by intracortical microstimulation applied to cortical sites in which an adjacent toe was represented. This is the type of result that would he predicted by the present findings. In monkeys, the presence of two or more foci of enhanced metabolic activity in the somatosensory cortex following repetitive stimulation of a finger ( $\mathrm{Ju}-$ liano et al., 1981; Juliano and Whitsel, 1987) would also be predicted by the present results. We suggest that these foci reflect the presence of a primary focus of projection, such as that demonstrated by the major concentration of retrogradely labeled cells ensuing from a single injection in the present study, and of one or more offshoot projections from other cells that commingle with the major concentration.

Medial lemniscal fibers, terminating in the monkey ventral posterior nucleus, do not branch widely and, instead, terminate in single, elongated, narrow territories (Jones, 1983). It is likely therefore that single fibers and groups of fibers arising from dorsal column or trigeminal nuclear cells with the same submodality and receptive field properties, will terminate mainly on a relatively small population of thalamic cells, most members of which project to the same locus in the cortex, as demonstrated in the present study. In this way, the basic fine grain projection of place and submodality from the dorsal column and principal trigeminal nuclei to the cortical map would be preserved. The focusing of lemniscal inputs onto clusters of thalamic cells that form parts of rods undoubtedly underlies the physiological observation that single units and multiunit clusters recorded over long anteroposterior distances in VPL and VPM tend to have the same receptive fields and submodality properties (Jones and Friedman, 1982; Jones et al., 1982, 1986a; Rausell and Jones, 1991a). We conjecture that these physiologically defined groups are the same as those in which the majority of cells projecting to a cortical dye injection site were labeled in the present study.

\section{A possible basis for representational plasticity}

A substantial number of cells in a main labeled thalamic cluster projects to regions of cortex more than $600 \mu \mathrm{m}$ distant from that receiving input from the principal population, overlap only ceasing with distances greater than $1.5 \mathrm{~mm}$. If we assume that these cells are synaptically engaged by the same lemniscal afferents as the majority population, a route is open for the projection of the place and submodality information carried by these lemniscal afferents to an apparently nonsomatotopically related locus in the cortex. At this second locus, the majority input should be from cells that form the majority population of its own related thalamic cluster, possibly forming part of a different thalamic rod or lamella. Under conditions in which the Inajority input to the second cortical locus is reduced-as in cases of peripheral deafferentation-the offshoot projection might be revealed. The fact that offshoot projections are formed by fewer thalamic cells than those that form the principal population suggests that under normal conditions the input from the primary population predominates. The presence of offshoot projections could, however, form the basis for the immediacy with which cortical representations mapped by multiunit recording can expand (Merzenich et al., 1983b; Cusick et al., 1990; Wall et al., 1992a,b), and makes it unnecessary to invoke axon sprouting as the primary mechanism of short-term plasticity.

Under conditions in which activity is enhanced in a set of lemniscal fibers as the result of passively or behaviorally increased stimulation of a small region of the body surface (Jenkins et al., 1990a,b; Recazone et al., 1992), the offshoot projection may show enhanced activity that would cause it to dominate the principal projection, thus giving the appearance of one part of the representation spreading at the expense of an adjacent part. A "cortical distance limit" of 1-1.5 mm for spread of a representation was originally proposed (Kaas et al., 1983) based on effects of forelimb digit amputation. This may be accounted for by the lack of overlap in thalamocortical projections demonstrated by injections more than $1.5 \mathrm{~mm}$ apart, although all injections in the present study were in the face or foot representations. The distance limit may be exceeded and reach 3-3.5 $\mathrm{mm}$ after appropriate combinations of peripheral nerve section (Garraghty et al., 1994). This may imply the presence of additional mechanisms outside the scope of the present study.

\section{Conclusion}

The present interpretations suggest that one basis for the form of the representational map in the somatic sensory cortex depends upon the lemniscal fibers, since it appears that the extent and position of a part of the representation relative to an adjacent part, at least in so far as it depends upon thalamic inputs, will 
depend upon the number of thalamocortical relay cells recruited by a place- and submodality-specific set of peripheral stimuli. But this is also to thrust the responsibility further upstream since it is likely that a pattern of input-output organization similar to that demonstrated in VP will exist in the dorsal column and principal trigeminal nuclei. The primary basis of a cortical map and of map plasticity is, thence, placed back at the periphery since it is the nature of the peripheral stimulus, especially if it involves the correlated activity of a population of peripheral receptors (Clark et al., 1988), that will determine the number of lemniscal axons activated and the extent and strength of activation of the thalamocortical relay cells that they recruit.

\section{References}

Allard T, Clark SA, Jenkins WM, Merzenich MM (1991) Reorganization of somatosensory area $3 \mathrm{~b}$ representations in adult owl monkeys after digital syndactyly. J Neurophysiol 66:1048-1058.

Benson DL, Isackson PJ, Hendry SHC, Jones EG (1991) Differential gene expression for glutamic acid decarboxylase and type II calciumcalmodulin-dependent protein kinase in basal ganglia, thalamus and hypothalamus of the monkey. J Neurosci 11:1540-1564.

Clark SA, Allard T, Jenkins WM, Merzenich MM (1988) Receptive fields in the body-surface map in adult cortex defined by temporally correlated inputs. Nature 332:444-445.

Cusick CG, Wall JT, Whiting JH, Wiley RG (1990) Temporal progression of cortical reorganization following nerve injury. Brain Res 537: 355-358.

Darian-Smith C., Darian-Smith I (1993) Thalamic projections to areas $3 \mathrm{a}, 3 \mathrm{~b}$, and 4 in the sensorimotor cortex of the mature and infant macaque monkey. J Comp Neurol 335:173-199.

Darian-Smith C, Darian-Smith I, Cheema SS (1990) Thalamic projections to sensorimotor cortex in the macaque monkey: use of multiple retrograde fluorescent tracers. J Comp Neurol 299:17-46.

Dreyer DA, Loe PR, Metz CB, Whitsel BL (1975) Representation of head and face in postcentral gyrus of the macaque. J Neurophysiol 38:714-734.

Garraghty PE, Sur M (1990) Morphology of single intracellularly stained axons terminating in area $3 b$ of macaque monkeys. J Comp Neurol 294:583-593.

Garraghty PE, Hanes DP, Florence SL, Kaas JH (1994) Pattern of peripheral deafferentation predicts reorganizational limits in adult primate somatosensory cortex. Somatosens Motor Res 11:109-117.

Hunt CA, Pang DZ, Jones EG (1991) Distribution and density of GABA cells in intralaminar and adjacent nuclei of monkey thalamus. Neuroscience 43:185-196.

Iwamura Y, Tanaka M, Sakamoto M, Hikosaka O (1983) Functional subdivisions representing different finger regions in area 3 of the first somatosensory cortex of the conscious monkey. Exp Brain Res 51: 315-326.

Iwamura Y, Tanaka M, Sakamoto M, Hikosaka O (1993) Rostrocaudal gradients in the neuronal receptive field complexity in the finger region of the alert monkey's postcentral gyrus. Exp Brain Res 92:360368 .

Jacobs KM, Donoghue JP (1991) Reshaping the cortical motor map by unmasking latent intracortical connections. Science 251:944-945.

Jcnkins WM, Mcrzenich MM, Ochs MT, Allard T, Guic-Robles E (1990) Functional reorganization of primary somatosensory cortex in adult owl monkeys after behaviorally controlled tactile stimulation. J Neurophysiol 63:82-104.

Jones EG (1983) Distribution patterns of individual medial lemniscal axons in thalamic ventrobasal complex of monkeys. J Comp Neurol $215: 1-16$

Jones EG (1985) The thalamus. New York: Plenum.

Jones EG (1990) The role of afferent activity in the maintenance of primate neocortical function. J Exp Biol 153:155-176.

Jones EG (1993) GABAergic neurons and their role in cortical plasticity in primates. Cereb Cortex 3:361-372.

Jones EG, Friedman DP (1982) Projection pattern of functional components of thalamic ventrobasal complex on monkey somatosensory cortex. J Neurophysiol 48:521-544.

Jones EG, Wise SP, Coulter JD (1979) Differential thalamic relation- ships of sensory motor and parietal cortical fields in monkeys. $J$ Comp Neurol 183:833-882.

Jones EG, Friedman DP, Hendry SHC (1982) Thalamic basis of place and modality-specific columns in monkey somatosensory cortex: a correlative anatomical and physiological study. J Neurophysiol 48 : $545-568$

Jones EG, Hendry SHC, Brandon C (1986a) Cytochrome oxidase staining reveals functional organization of monkey somatosensory thalamus. Exp Brain Res 62:438-442.

Jones EG, Schwark HD, Callahan PJ (1986b) Extent of the ipsilateral representation in the ventral posterior medial nucleus of the monkey thalamus. Exp Brain Res 63:310-320.

Juliano SL, Whitsel BL (1987) A combined 2-deoxyglucose and neurophysiological study of primate somatosensory cortex. J Comp Neurol 263:514-525.

Juliano SL, Hand PJ, Whitsel BL (1981) Patterns of increased metabolic activity in the somatosensory cortex of monkeys (Macaca fascicularis) subjected to controlled cutaneous stimulation: a 2-deoxyglucose study. J Neurophysiol 46:1260-1284.

Kaas JH (1991) Plasticity of sensory and motor cortical maps in adult mammals. Annu Rev Ncurosci 14:137-167.

Kaas JH, Nelson RJ, Sur M, Lin C-S, Merzenich MM (1979) Multiple representations of the body within the primary somatosensory cortex of primates. Science 204:521-523.

Kaas JH, Merzenich MM, Killackey HP (1983) The reorganization of the somatosensory cortex following peripheral nerve damage in adult and developing mammals. Annu Rev Neurosci 6:325-356.

Kaas JH, Pons TP, Wall JT, Garraghty PE, Cusick CG (1987) Consistent features of the representation of the hand in area $3 \mathrm{~b}$ of macaque monkeys. Somatosens Res 4:309-331.

Lund JP, Sun G-D, Lamarre Y (1994) Cortical reorganization and deafferentation in adult macaques. Science 265:546-548

Ma W, Juliano S (1991) The relationship between thalamocortical connections and stimulus-evoked metabolic activity in the ventroposterior nucleus of the monkey. Sonnatosens Motor Res 8:77-86.

Merzenich MM, Kaas JH, Sur M, Lin CS (1978) Double representation of the body surface within cytoarchitectonic areas $3 b$ and 1 in SI in the owl monkey (Aotus trivirgatus). J Comp Neurol 181:41-74.

Merzenich MM, Kaas JH, Wall J, Nelson RJ, Sur M, Felleman D (1983a) Topographic reorganization of somatosensory cortical areas $3 \mathrm{~B}$ and 1 in adult monkeys following restricted deafferentation. Neuroscience 8:33-56.

Merzenich MM, Kaas JH, Wall JT, Sur M, Nelson RJ, Felleman DJ (1983b) Progression of change following median nerve section in the cortical representation of the hand in areas $3 \mathrm{~b}$ and 1 in adult owl and squirrel monkeys. Neuroscience 10:639-666.

Merzenich MM, Nelson RJ, Kaas JH, Stryker MP, Jenkins WM, Zook JM, Cynader MS, Schoppmann A (1987) Variability in hand surface representations in areas $3 \mathrm{~b}$ and 1 in adult owl and squirrel monkeys. J Comp Neurol 258:281-296.

Mountcastle VB (1984) Central nervous mechanisms in mechanoreceptive sensibility. In: Handbook of physiology, Sect I, The nervous system, Vol 3, Sensory processes, Pt 1 (Brookhart JM, Mountcastle VB, Darian-Smith I, eds), pp 789-878. Bethesda, MD: American Physiological Society.

Mountcastle VB, Henneman E (1952) The representation of tactile sensibility in the thalamus of the monkey. J Comp Neurol 97:109-139.

Mountcastle VB, Powell TPS (1959) Central nervous mechanisms subserving position sense and kinesthesis. Bull Johns Hopkins Hosp 105: 173-200

Nelson RJ, Kaas JH (1981) Connections of the ventroposterior nucleus of the thalamus with the body surface representations in cortical areas $3 \mathrm{~b}$ and $\mathrm{I}$ of the cynomolgus macaque (Macaca fascicularis). J Comp Neurol 199:29-64.

Nelson RJ, Sur M, Felleman DJ, Kaas JH (1980) Representations of the body surface in post-central parietal cortex of Macaca fascicularis. J Comp Neurol 192:611-643.

Paul RL, Merzenich M, Goodman H (1972) Representation of slowly and rapidly adapting cutaneous mechanoreceptors of the hand in Brodmann's areas 3 and 1 of Macaca mulatta. Brain Res 36:229249.

Phillips CG, Powell TPS, Wiesendanger M (1970) Projection from low-threshold muscle afferents of hand and forearm to area $3 \mathrm{a}$ of baboon's cortex. J Physiol (Lond) 210:59-60.

Poggio GF, Mountcastle VB (1963) The functional properties of ven- 
trobasal thalamic neurons studied in unanesthetized monkeys. J Neurophysiol 26:775-806.

Pons TP, Garraghty PE, Ommaya AK, Kaas JH, Taub E, Mishkin M (1991) Massive cortical reorganization after sensory deafferentation in adult macaques. Science 252:1857-1860.

Powell TPS, Mountcastle VB (1959a) The cytoarchitecture of the postcentral gyrus of the monkey Macaca mulatta. Bull Johns Hopkins Hosp 105:108-131.

Powell TPS, Mountcastle VB (1959b) Some aspects of the functional organization of the cortex of the postcentral gyrus of the monkey: a correlation of findings obtained in a single unit analysis with cytoarchitecture. Bull Johns Hopkins Hosp 105:133-162.

Rausell E, Jones EG (1991a) Histochemical and immunocytochemical compartments of the thalamic VPM nucleus in monkeys and their relationship to the representational map. J Neurosci 11:210-225.

Rausell E, Jones EG (1991b) Chemically distinct compartments of the thalamic VPM nucleus in monkeys relay principal and spinal trigeminal pathways to different layers of the somatosensory cortex. J Neurosci 11:226-237.

Rausell E, Bae CS, Viñuela A, Huntley GW, Jones EG (1992) Calbindin and parvalbumin cells in monkey VPL thalamic nucleus: distribution, laminar cortical projections, and relations to spinothalamic terminations. J Neurosci 12:4088-4111.

Rausell E, Molinari M, Iones FG (1993) Divergence in the projection of ventrobasal thalamic neurons to monkey somatosensory cortex. Soc Neurosci Abstr 19:1567.

Recanzone GH, Mcrzenich MM, Jcnkins WM, Grajski KA, Dinse IIR (1992) Topographic reorganization of the hand representation in cortical area $3 \mathrm{~b}$ of owl monkeys trained in a frequency-discrimination task. J Neurophysiol 67:1031-1056.

Roberts TS, Akert K (1963) Insular and opercular cortex and its tha- lamic projection in Macaca mulatta. Schweiz Arch Neurol Neurochir Psychiatry 92:1-13.

Rose JE, Mountcastle VB (1959) Touch and kinesthesis. In: Handbook of physiology (Field J, Magoun HW, Hall VE, eds), pp 387-429. Washington, DC: American Physiological Society.

Snow PJ, Nudo RJ, Rivers W, Jenkins WM, Merzenich MM (1988) Somatotopically inappropriate projections from thalamocortical neurons to the SI cortex of the cat demonstrated by the use of intracortical microstimulation. Somatosens Res 5:349-372.

Sur M, Merzenich MM, Kaas JH (1980) Magnification, receptive-field area, and "hypercolumn" size in areas $3 b$ and 1 of somatosensory cortex in owl monkeys. J Neurophysiol 44:295-311.

Sur M, Wall JT, Kaas JH (1981) Modular segregation of functional cell classes within the postcentral somatosensory cortex of monkeys. Science 212:1059-1061.

Sur M, Wall IT, Kaas JH (1984) Modular distribution of neurons with slowly adapting and rapidly adapting responses in area $3 \mathrm{~b}$ of somatosensory cortex in monkeys. J Neurophysiol 51:724-744.

Wall JT, Kaas JH, Sur M, Nelson RJ, Felleman DJ, Merzenich MM (1986) Functional reorganization in somatosensory cortical areas $3 b$ and 1 of adult monkeys after median nerve repair: possible relationships to sensory recovery in humans. J Neurosci 6:218-233.

Wall JT, Huerta MF, Kaas JH (1992) Changes in the cortical map of the hand following postnatal median nerve injury in monkeys modification of somatotopic aggregates. J Neurosci 12:3445-3455.

Wall JT, Nepomuceno V, Rasey SK (1993) Nerve innervation of the hand and associated nerve dominance aggregates in the somatosensory cortex of a primate (squirrel monkey). J Comp Neurol 337:191207.

Wong-Riley M (1979) Changes in the visual system of monocularly sutured or enucleated cats demonstrable with cytochrome oxidase histochemistry. Brain Res 171:11-28. 